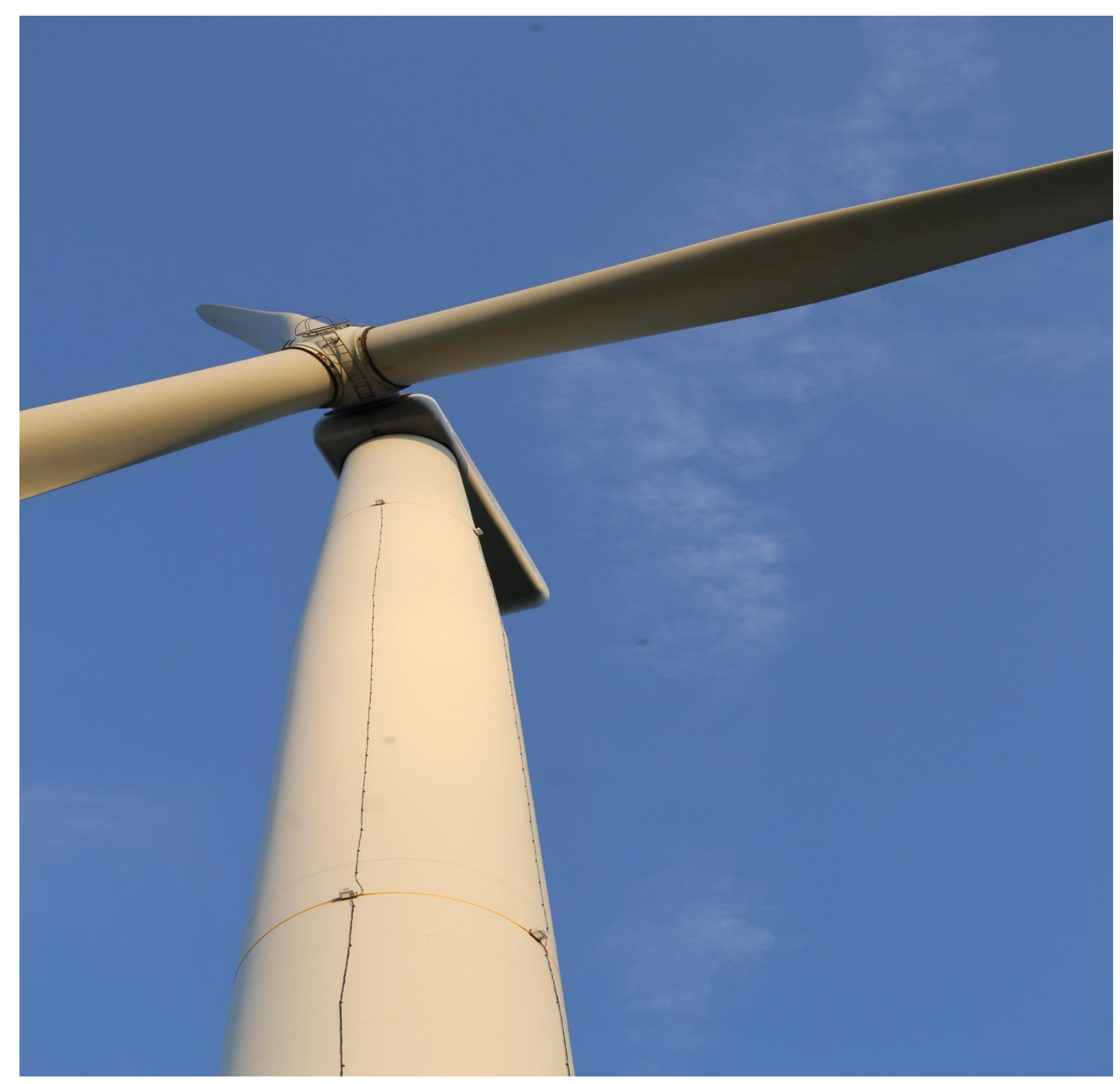

\title{
Bat flight analysis around wind turbines - a feasibility study
}

Authors: Sander Lagerveld, Gert Kooistra, Gerwoud Otten, Lydia Meesters, Jasper Manshanden, Dick de Haan, Daan Gerla, Hans Verhoef \& Michaela Scholl
Wageningen University \&

Research Report C026/17 


\section{Bat flight analysis around wind turbines - a feasibility study}

Author(s): $\quad$ Sander Lagerveld, Gert Kooistra ${ }^{1}$, Gerwoud Otten $^{1}$, Lydia Meesters ${ }^{1}$, Jasper Manshanden, Dick de Haan, Daan Gerla, Hans Verhoef ${ }^{2}$ \& Michaela Scholl

Publication date: 31 March 2017

Wageningen Marine Research

Den Helder, March 2017

Wageningen Marine Research report C026/17

${ }^{1}$ Computer Vision research group of Wageningen Food \& Biobased Research (WFBR)

2 Energy Research Centre Netherlands 
Sander Lagerveld, Gert Kooistra, Gerwoud Otten1, Lydia Meesters1, Jasper Manshanden, Dick de Haan, Daan Gerla, Hans Verhoef2 \& Michaela Scholl, 2017. Bat flight analysis around wind turbines - a feasibility study; Wageningen, Wageningen Marine Research (University \& Research Centre), Wageningen Marine Research report C026/17. 40 p.

Keywords: migratory bats, offshore wind farms, behaviour, fatalities, barotrauma, collision, feasibility study.

Client: $\quad$ Rijkswaterstaat

Water, Verkeer en Leefomgeving

Postbus 2232, 3500 GE Utrecht

Zaaknummer 3117989/de Jong

This research was part of the WOZEP programme ('offshore wind ecological programme'), commissioned by Rijkswaterstaat and (co-)financed by the Ministry of Economic Affairs for the purposes of Policy Support Research Theme 'Wind op Zee' (Kennisbasisproject KB24-001-001).

Wageningen Marine Research is ISO 9001:2008 certified.

This report is free to download from https://doi.org/10.18174/417091

Wageningen Marine Research provides no printed copies of reports.

(C) 2017 Wageningen Marine Research Wageningen UR

Wageningen Marine Research The Management of Wageningen Marine Research is not responsible for resulting institute of Stichting Wageningen damage, as well as for damage resulting from the application of results or Research is registered in the Dutch research obtained by Wageningen Marine Research, its clients or any claims traderecord nr. 09098104, related to the application of information found within its research. This report BTW nr. NL 806511618 has been made on the request of the client and is wholly the client's property. This report may not be reproduced and/or published partially or in its entirety without the express written consent of the client. 


\section{Contents}

Summary

$1 \quad$ Introduction

$\begin{array}{llr}1.1 & \text { Assignment } & 8\end{array}$

$\begin{array}{llr}1.2 & \text { The project team } & 8\end{array}$

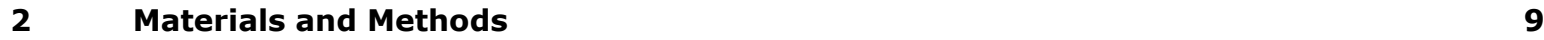

$\begin{array}{llr}2.1 & \text { Study area } & 9\end{array}$

$\begin{array}{llr}2.2 & \text { Bat detector } & 9\end{array}$

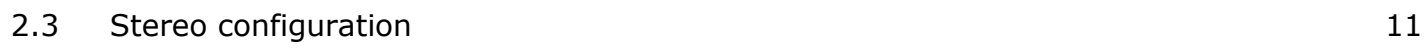

$\begin{array}{lll}2.4 & \text { Monitoring effort } & 13\end{array}$

$\begin{array}{ll}2.5 & \text { Comparison of acoustic and flight path data } \\ \end{array}$

3 Design of the equipment $\quad 15$

$\begin{array}{llr}3.1 & \text { Acoustic monitoring } & 15\end{array}$

$\begin{array}{lll}3.2 & \text { Stereo configuration } & 15\end{array}$

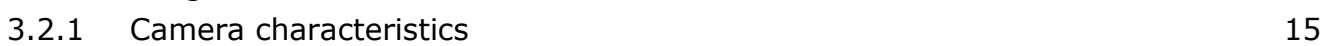

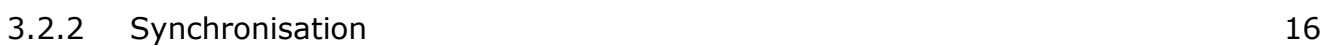

$\begin{array}{ll}3.2 .3 \text { Accuracy } & 17\end{array}$

$\begin{array}{lll}3.2 .4 & \text { Calibration } & 21\end{array}$

$\begin{array}{lll}3.2 .5 & \text { Tracking moving objects } & 23\end{array}$

$4 \quad$ Results $\quad 27$

$\begin{array}{llr}4.1 & \text { Bat detector } & 27\end{array}$

$\begin{array}{lll}4.1 .1 & \text { Performance } & 27\end{array}$

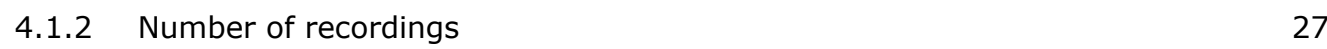

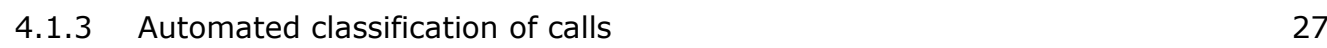

$\begin{array}{lll}4.2 & \text { Flight path visualisation } & 28\end{array}$

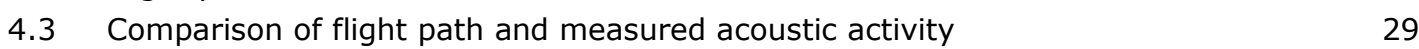

5 Discussion and Conclusions $\quad 31$

$\begin{array}{lll}5.1 & \text { Acoustic monitoring } & 31\end{array}$

$\begin{array}{lll}5.2 & \text { Stereo configuration } & 31\end{array}$

$\begin{array}{llr}6 & \text { Recommendations } & 33\end{array}$

$\begin{array}{llr}7 & \text { Quality Assurance } & 35\end{array}$

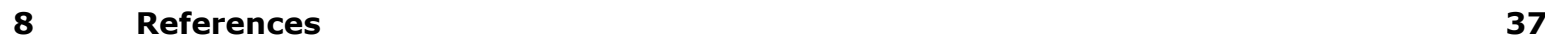

$\begin{array}{lr}\text { Justification } & 39\end{array}$ 


\section{Summary}

In recent years, research into the occurrence of bats at the Dutch North Sea has shown that there is regular seasonal migration over sea. However, so far, little is known about their migration ecology, the fatality risks at offshore wind turbines, and the number of individuals migrating over sea. Since the Dutch government wants to boost the further development of wind energy production in the southern North Sea, the Ministry of Economic Affairs commissioned to Rijkswaterstaat the elaboration of an integrated Wind at Sea Ecological Programme (in Dutch: Wozep).

This study, as part of the Wozep-project Behaviour and Collision Risk of Bats (Bats_2), investigates how bat behaviour can be studied near offshore wind turbines. To find out whether it is wise to continue and further develop behavioural research at wind turbines in the context of the Wozep programme, we first conducted a feasibility study on land.

A stereoscopic setup consisting of two thermal cameras was devised and used to collect footage of bats in August and September 2016 at the Wind Turbine test Site in the Wieringermeer. The cameras were positioned in such a way that the overlapping field of view in both cameras could be used to determine 3D bat paths at a distance of $80 \mathrm{~m}$ around a single wind turbine. In addition, acoustic bat activity was measured with a 12 channel bat detector at three different heights with microphones in each wind direction.

Tailor made 3D analysis tools were developed to synchronize both thermal cameras, calibrate the stereoscopic setup, determine 2D tracks in the left and the right view and eventually to reconstruct the $x, y, z$ coordinates of bat positions in time. The results are promising and show that the current hardware and computer vision analysis tools can be used to derive 3D bat trajectories in space and time. With the current system a bat can be detected at $80 \mathrm{~m}$ from the cameras with an accuracy of $8.5 \mathrm{~cm}$ of the $x$ - and $y$-coordinates and an accuracy of $50 \mathrm{~cm}$ of the estimated depth (z-coordinate) at a camera base distance of 8 meters. The accuracy depends on the stereo setup characteristics and is an interaction between parameters such as camera resolution, camera base distance and camera distance to the bats. Calibration of the stereo setup was challenging because of the large camera base distance and the vertical orientation of the stereo setup.

Although a 3D path can be derived with the current thermal cameras, better quality images can be obtained with cameras that offer more control. The 2D tracking algorithms will benefit from better quality images and become more robust. Within the context of this feasibility study we have focused on the proof of concept and not all 3D analysis processes are fully automated. At this moment, manual input is needed to identify $3 \mathrm{D}$ bat tracks. An automatic procedure to detect the bats and not the insects or clouds still needs to be developed.

The conclusion of this feasibility study is that computer vision components can be used to measure bat flight trajectories in 3D to study the effects of wind turbines on the bat mortality and bat flight behaviour. The bat detector configuration is able monitor bat activity simultaneously at multiple heights in different directions, which can be used for species identification and to assess the accuracy of the estimated bat flight trajectories. During nights with much bat activity several thousand recordings can be obtained and therefore it is necessary to identify these automatically.

Before a system can be built for wind turbines at sea, further improvements are needed to mature the current system and meet the goal to automatically detect bat fight paths and fatalities. Before application at sea we recommend to build a prototype on land with multiple stereo setups to monitor the complete area of the rotors and improve and automatize the current 3D analysis tools. 
In recent years, exploratory research into the occurrence of bats at the Dutch North Sea has shown that there is regular seasonal migration over sea of at least Nathusius' pipistrelle Pipistrellus nathusii but perhaps also of parti-coloured bat Vespertilio murinus and common noctule Nyctalus noctula (Boshamer \& Bekker 2008, Jonge Poerink et al. 2013, Lagerveld et al. 2014a, 2014b, 2015, Leopold et al. 2014).

Given the fact that the Dutch government wants to boost the further development and expansion of wind farms in the Dutch part of the southern North Sea in the coming years (SER agreement 2013), and the growing evidence that bats are vulnerable to barotrauma and collisions with wind turbines (e.g. Baerwald et al. 2008, Bach et al. 2014, Cryan et al. 2014), the Ministry of Economic Affairs commissioned to Rijkswaterstaat (RWS) a two-year monitoring programme in 2015 to establish a systematic inventory of the actual occurrence of bats over the North Sea. This study is currently being conducted in a project titled 'Research on distribution and behaviour of bats in the southern North Sea' (RWS case number 31103115). It aims at providing insight into bat movements over sea: which bat species do occur, in what numbers, at what times, and how does that relate to weather conditions? If there is a relationship, a risk assessment based on timing and weather conditions could be carried out. To determine the presence of bats, the study uses ultrasound bat detectors. However, translating 'call records' into numbers of individuals is not possible without understanding the underlying individual behavioural patterns of bats in offshore wind farms, e.g. stopover and recurrence behaviour. After all, when individuals spend an extended period of time around a wind turbine, their number in relation to the number of 'call records' will be lower than if the registrations were concerning individuals passing through more rapidly.

In order to be able to make better estimates of the actual numbers of bats at sea, more research is needed into their migration behaviour in general as well as their specific behaviour in (the vicinity of) offshore wind farms. At this moment it is not clear which proportion of the population migrates over sea and which proportion travels over land. Behavioural research at offshore wind farms is expected to provide the information required to estimate the number of (potential) fatalities and possibly to predict more accurately when and under what circumstances the fatality risk becomes so high that it would be better to stop the turbines. The more precise these predictions, the shorter the downtimes and revenue losses for the wind farm operators when compared to the situation where, due to lack of knowledge, wind turbines must be shut down for a longer period of time out of precaution.

When assessing the overall effect of offshore wind farms on migratory bats, three questions are central to the subject:

1) Which part of the population passing through the Netherlands migrates over sea, and which part over land?

2) Are bats migrating over sea attracted to offshore wind turbines, and if so, to what distance?

3) What exactly is the behaviour of bats in the immediate vicinity of a wind turbine?

The overall effect of offshore wind farms on migratory bats will be largest when (1) a large proportion of the migrating bats moves over sea (2), migrating bats exhibit strong attraction to wind turbines, at a relatively large distance, and (3) individuals, displaying intensive flying/ foraging behaviour, spend much time in the vicinity of a wind turbine, thereby running a high risk of collision and/or barotrauma.

Studying bat behaviour therefore should be done at three different spatial scales: on the scale of an individual turbine and its immediate surroundings (i.c. the rotor swept area RSA), on the scale of a wind farm and on the scale outside (offshore) wind farms. The use of thermal cameras and bat detectors makes it possible to study the behaviour of bats near wind turbines in more detail, while telemetry appears to be a suitable technique to study the flight behaviour of bats (and birds) on a 
larger scale (Lagerveld et al. in prep, Francis et al. 2016, Janssen et al. 2016, Kays et al. 2011, Körner et al. 2010, Rerucha et al. 2014, Sjöberg et al. 2015, Smolinsky et al. 2013).

The main research questions which have to be addressed when performing behavioural research at offshore wind turbines are:

1) What is the flight behaviour of bats in the vicinity of offshore wind turbines, i.e. how long do they stay, at which heights and at what distances from the rotor blades?

2) What is the risk of individuals bats to collide with an offshore wind turbine or become victim of barotrauma?

3) Can reliable estimates be obtained of the number of bats which pass through offshore wind farms and over the southern North Sea in general, when behavioural data is combined with bat detector data?

4) Is it possible to estimate the actual number of victims at the southern North Sea?

Eventually, the answers to these questions should - in combination with telemetry research- provide a clearer picture of what is the overall effect of offshore wind farms on migratory bats over the North Sea.

Aim of this project is to investigate the feasibility of the measurement set-up for the application of behavioural research of bats (and possibly also birds) in the proximity of wind turbines. The measurement setup consists of 12 ultrasonic microphones which are able to detect echolocation calls of bats at different heights and in four wind directions around the turbine mast in combination with a stereo-set of thermal imaging cameras to record the actual bat flight paths.

The results and conclusions of this feasibility study should answer the question of whether it is wise to continue and further develop this type of research in the coming years, and which is the best way to implement this research for migratory bats in the context of the Wozep programme (see section 1.1).

\section{$1.1 \quad$ Assignment}

This present study titled Behaviour and Collision Risk of Bats (Bats_2), was commissioned by RWS and is part of the Wind op Zee Ecologisch Programma (Wozep; in English: Wind at Sea Ecological Programme), a multi-annual research programme initiated in view of the realisation of new offshore wind farms under the SER agreement (2013). The study comprises two parts: 1) Telemetry for migratory bats, and 2) Bat behaviour at wind turbines. The second part is reported here; the first part will be accounted for in a separate report.

\subsection{The project team}

The project team conducting this study consists of employees of Wageningen Marine Research (Dick de Haan, Daan Gerla, Sander Lagerveld, Jasper Manshanden and Michaela Scholl), Wageningen Food \& Biobased Research (Gert Kooistra, Gerwoud Otten and Lydia Meesters), and the Energy research Centre Netherlands (Hans Verhoef).

Wageningen Marine Research has the project leadership, developed the concept of the measurement setup and designed and realised the acoustic monitoring structure. Wageningen Food \& Biobased Research Bionet Nature Research developed the calibration and computer vision algorithms. The Energy research Centre Netherlands provided the wind turbine for the actual field tests and technical assistance to implement the bat detector configuration. 


\section{Materials and Methods}

\section{$2.1 \quad$ Study area}

This feasibility study was conducted at the Nordex 5 turbine at the Wind Turbine test Site of the Energy research Centre Netherlands (ECN) in the Wieringermeer. The test turbine comprised a Nordex $\mathrm{N} 80$ wind turbine with a hub height and rotor dimeter of $80 \mathrm{~m}$, and a rated power of $2.5 \mathrm{MW}$.

\section{$2.2 \quad$ Bat detector}

Bats emit high frequency calls for navigation. This echolocation system enables them to orientate and to catch prey in the dark. The frequency of most bat calls is beyond the human hearing but can be recorded by an ultrasonic detector (bat detector). The detection range depends on the environmental conditions, quality and settings of the bat detector and is species-specific. Smaller species like common pipistrelle Pipistrellus pipistrellus and Nathusius' pipistrelle Pipistrellus nathusii are in general recorded within a range of 15-25 m, whereas large bats like common noctule Nyctalus noctula and serotine bat Eptesicus serotinus can sometimes be recorded over 100 meter.

In addition to echolocation calls, bats also use social calls to interact with other individuals. Some species of bat can be diagnostically identified to species level, but it is common that individual bats are identified to genus (e.g. Myotis) or species-group level (e.g. Nycataloid, which includes the genera Nyctalus, Eptesicus, Vespertilio, Tadarida).

For the acoustic monitoring we used the Avisoft-UltraSoundGate $1216 \mathrm{H}$; an ultrasound recording interface with balanced analog inputs which was connected to a $8 \mathrm{~GB}, 3.4 \mathrm{GHz}$ PC with Intel I5 processor. We used 12 Electret ultrasound microphones FG-DT50 with a remote-controlled reference signal generator and USB-powered heating. The microphones were embedded in waterproof boxes and placed in four different directions at three different heights $(5,35 \& 65$ meter) at the turbine tower (Figure 1 and 2). XLR microphone extension cables and heating wires were used to connect the microphones with the UltraSoundGate. The batdetector configuration was installed 25 August 2016. By the end of September a network connection was established in order to monitor the performance of the bat detector and to retrieve the monitoring data. 

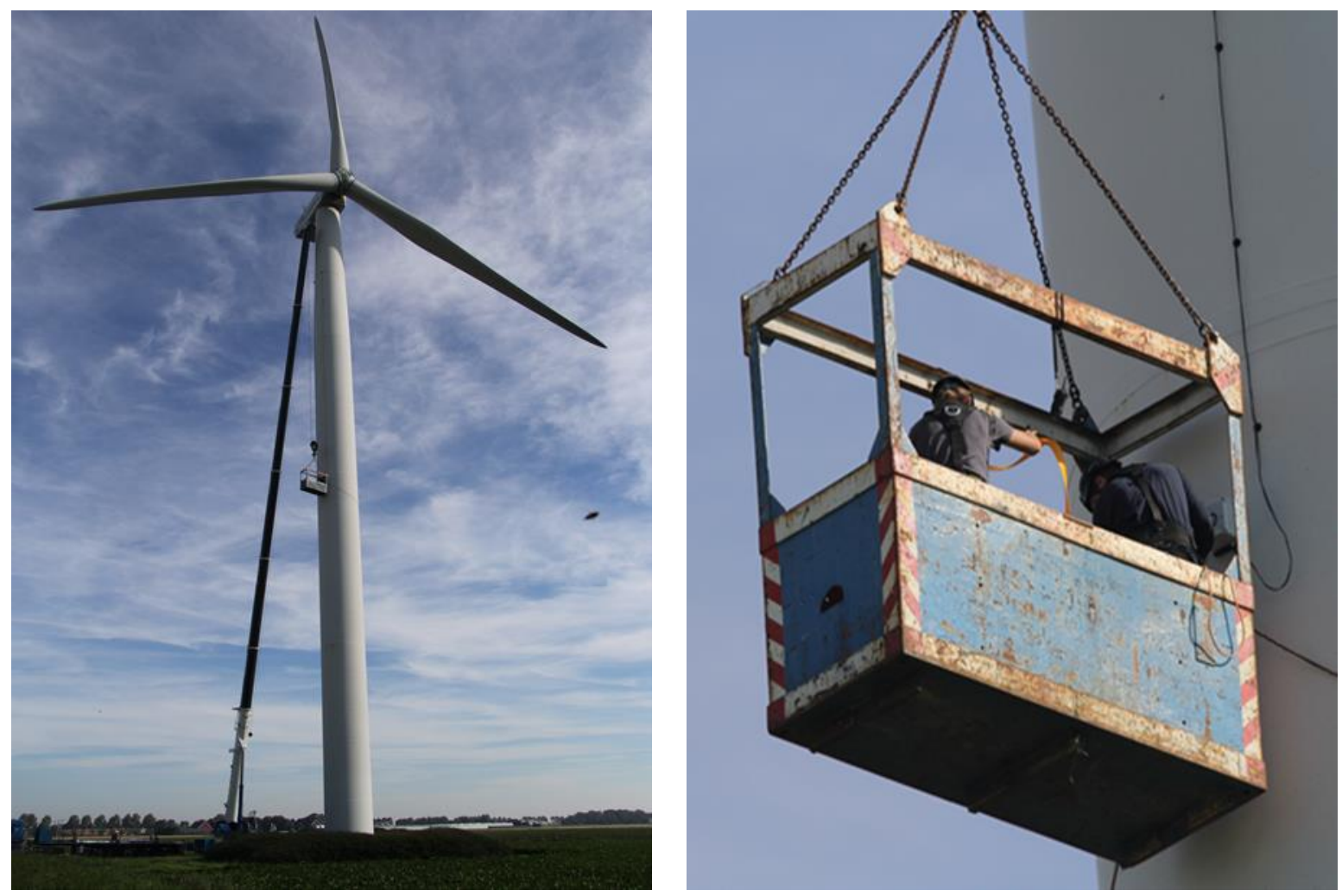

Figure 1: the installation of the bat detector required a heavy crane. The microphones were orientated southwest, northwest, northeast and southeast at three different heights (5, 35 and $65 \mathrm{~m}$ ). Photo: Sander Lagerveld

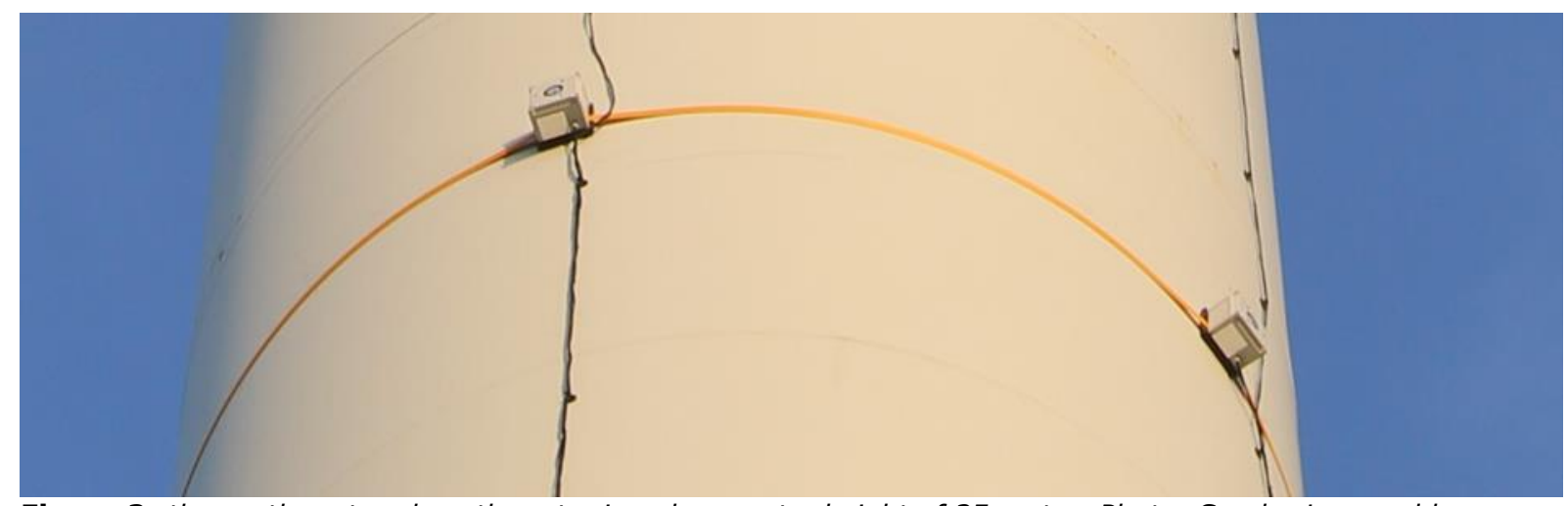

Figure 2: the northwest and southwest microphones at a height of 35 meter. Photo: Sander Lagerveld

For analysing the recordings of the bat detector we used Avisoft SASlab Pro. In this programme there are various options for automated classification of bat calls. For this (rural) monitoring location where migration can be expected we considered common noctule Nyctalus noctula, Leister's bat Nyctalus leisleri, serotine bat Eptesicus serotinus, particoloured bat Vespertilio murinus, pond bat Myotis dasycneme, Daubenton's bat Myotis daubentonii , common pipistrelle Pipistrellus pipistrellus, Nathusius 'pipistrelle Pipistrellus nathusii and soprano pipistrelle Pipistrellus pygmeus relevant species. 
For testing the feasibility of automated identification we tested a stratified (per microphone) random sample of 96 recordings which were obtained between 25 August and 8 September. We first identified each recording manually using the identification criteria of Barataud 2016. Then, we tried two different algorithms for the automated identification;

1. Identification by acoustic parameters; bat calls are identified by a user defined value of an acoustic parameter, or a combination of parameters. Table 1 shows the parameter settings we used.

Table 1: At first individual call elements are classified as either quasi-constant frequency (QCF) or frequency modulated (FM) signals based on the bandwidth (difference between highest and lowest frequency). Subsequent classification occurs by a combination of the acoustic properties of the call element which were based on Barataud 2016.

\begin{tabular}{|c|c|c|c|c|c|c|c|c|c|}
\hline \multirow[b]{2}{*}{$\begin{array}{l}\text { Type of } \\
\text { signal }\end{array}$} & \multirow[b]{2}{*}{ Species(group) } & \multicolumn{2}{|c|}{$\begin{array}{c}\text { Bandwidth } \\
{[\mathrm{kHz}]}\end{array}$} & \multicolumn{2}{|c|}{$\begin{array}{c}\text { Peak frequecy } \\
{[\mathrm{kHz}]}\end{array}$} & \multicolumn{2}{|c|}{$\begin{array}{c}\text { End } \\
\text { frequency } \\
{[\mathrm{kHz}]}\end{array}$} & \multicolumn{2}{|c|}{ Duration [ms] } \\
\hline & & Min & Max & Min & Max & Min & $\operatorname{Max}$ & Min & Max \\
\hline \multirow{7}{*}{$\begin{array}{c}\text { QCF } \\
\text { (bandwidth } \\
0-5 \mathrm{kHz} \text { ) }\end{array}$} & Nyctaloid & & & 21 & 35 & & & 10 & 26 \\
\hline & Nyctalus noctula & & & 16 & 21 & & & & \\
\hline & Nyctalus leisleri & & & 21 & 35 & & & 5 & 10 \\
\hline & Pipistrelloid & & & & & 40 & 42 & & 16 \\
\hline & Pipistrellus pipistrellus & & & & & 42 & 50 & & 16 \\
\hline & Pipistrellus nathusii & & & & & 35 & 40 & & 16 \\
\hline & Pipistrellus pygmaeus & & & & & 50 & 60 & & 16 \\
\hline \multirow{8}{*}{$\begin{array}{c}\text { FM-QCF } \\
\text { (bandwidth } \\
>5 \mathrm{kHz} \text { ) }\end{array}$} & Nyctaloid & 5 & 40 & 20 & 33 & 20 & 30 & & 20 \\
\hline & Eptesicus serotinus & 40 & 60 & & & 29 & 33 & & 20 \\
\hline & Pipistrelloid & 5 & 80 & & 45 & 40 & 42 & & 12 \\
\hline & Pipistrellus pipistrellus & 5 & 80 & & 51 & 42 & 50 & & 12 \\
\hline & Pipistrellus nathusii & 5 & 80 & & 41 & 33 & 40 & & 12 \\
\hline & Pipistrellus pygmaeus & 5 & 80 & & 67 & 50 & 64 & & 12 \\
\hline & $\begin{array}{l}\text { Myotis } \\
\text { daubentonii/dasycneme }\end{array}$ & 5 & 40 & 31 & 38 & 20 & 31 & & 30 \\
\hline & 'Noise' & & & & 14 & & & & 15 \\
\hline
\end{tabular}

2. Identification by reference calls; bat calls are identified through cross-correlation with a database of reference calls. For the reference calls we used the recordings by Barataud 2016 of the species we considered relevant (see above).

\subsection{Stereo configuration}

The devised flexible stereo camera configuration can capture the wind turbine rotors and electrical generator from any direction of wind. The stereo setup was developed to record bats at a height of 80 $\mathrm{m}$ around the wind turbine (the nacelle height). 


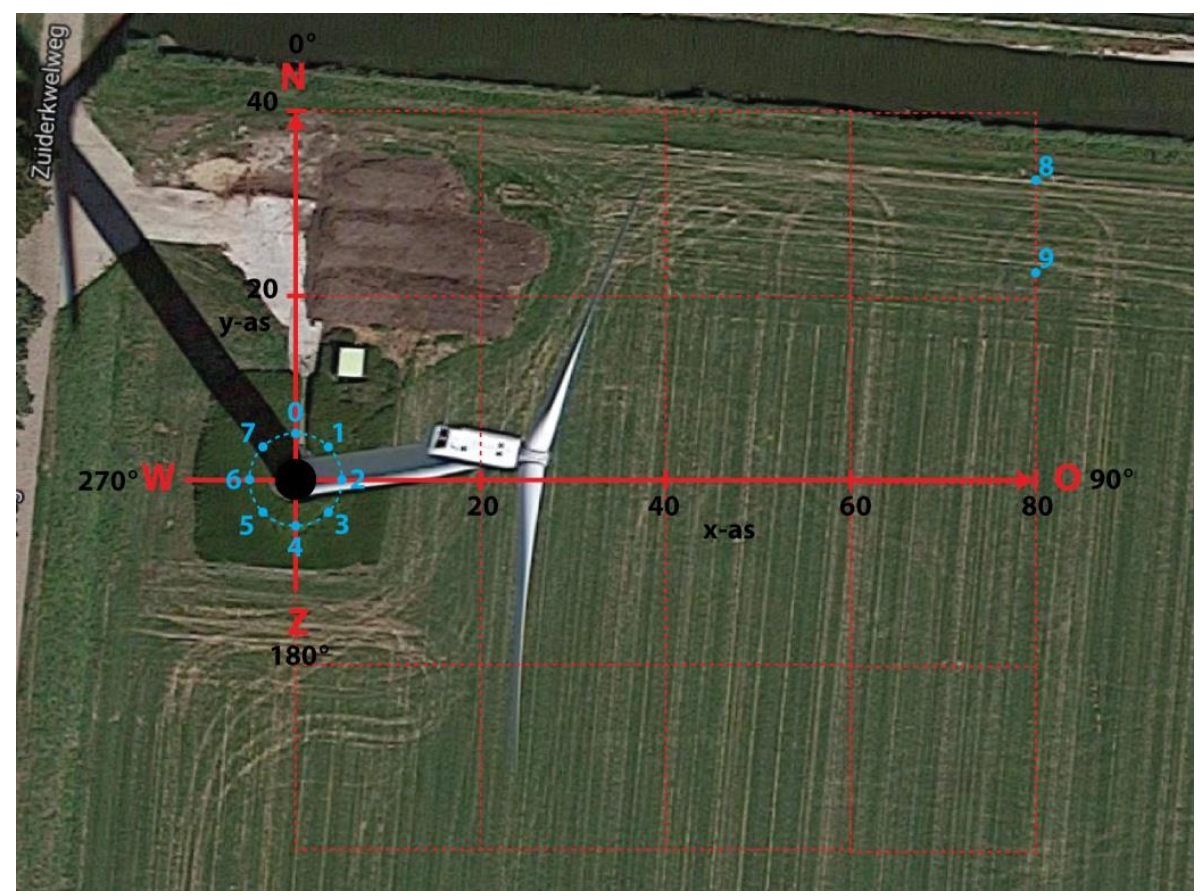

Figure 3: Top view of the wind turbine. Marked are the poles and optional camera positions 0-9 (blue). The camera positions of the horizontal view are indicated by 8-9. The possible camera positions for a vertical view are given by $0-7$.

The rotor is pointed into the wind during production. The position of both cameras depends on the wind turbine orientation because the rotors need to be in sight in the camera images. Therefore a number of wooden poles (see Figure ) had to be drilled into the soil around the wind turbine. The poles are positioned in such a way that the two thermal cameras can be mounted on top of any two poles while the tur

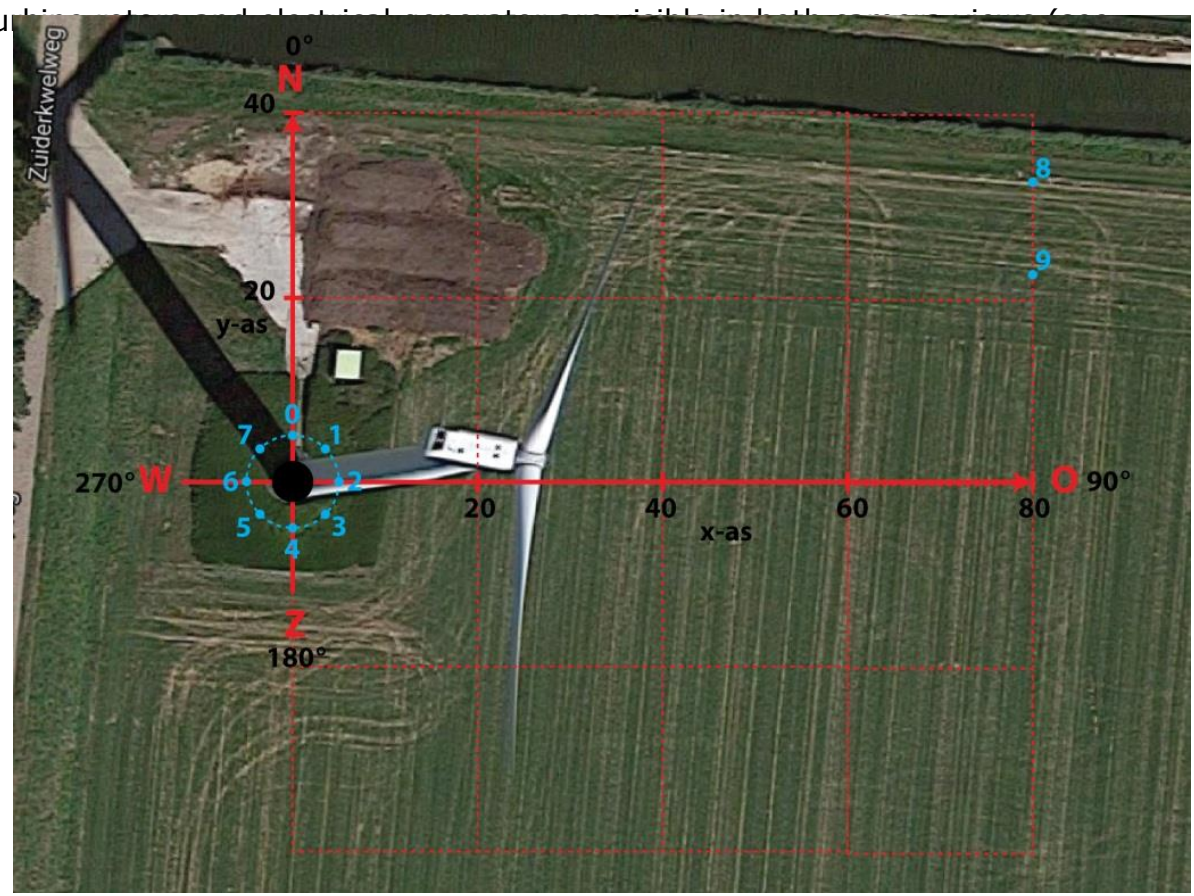

Figure ). 


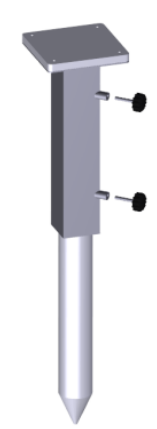

Figure 4: Example of a wooden pole and the construction to mount a thermal camera.

The footage was collected with three stereo setups:

1. A vertical view close to the wind turbine where the distance between the two cameras is \pm 1 $1.5 \mathrm{~m}$ (see

3. Figure camera position 0-7 and 5 (b)).

4. A vertical view close to the wind turbine where the distance between both cameras is $\pm 8 \mathrm{~m}$ (see 


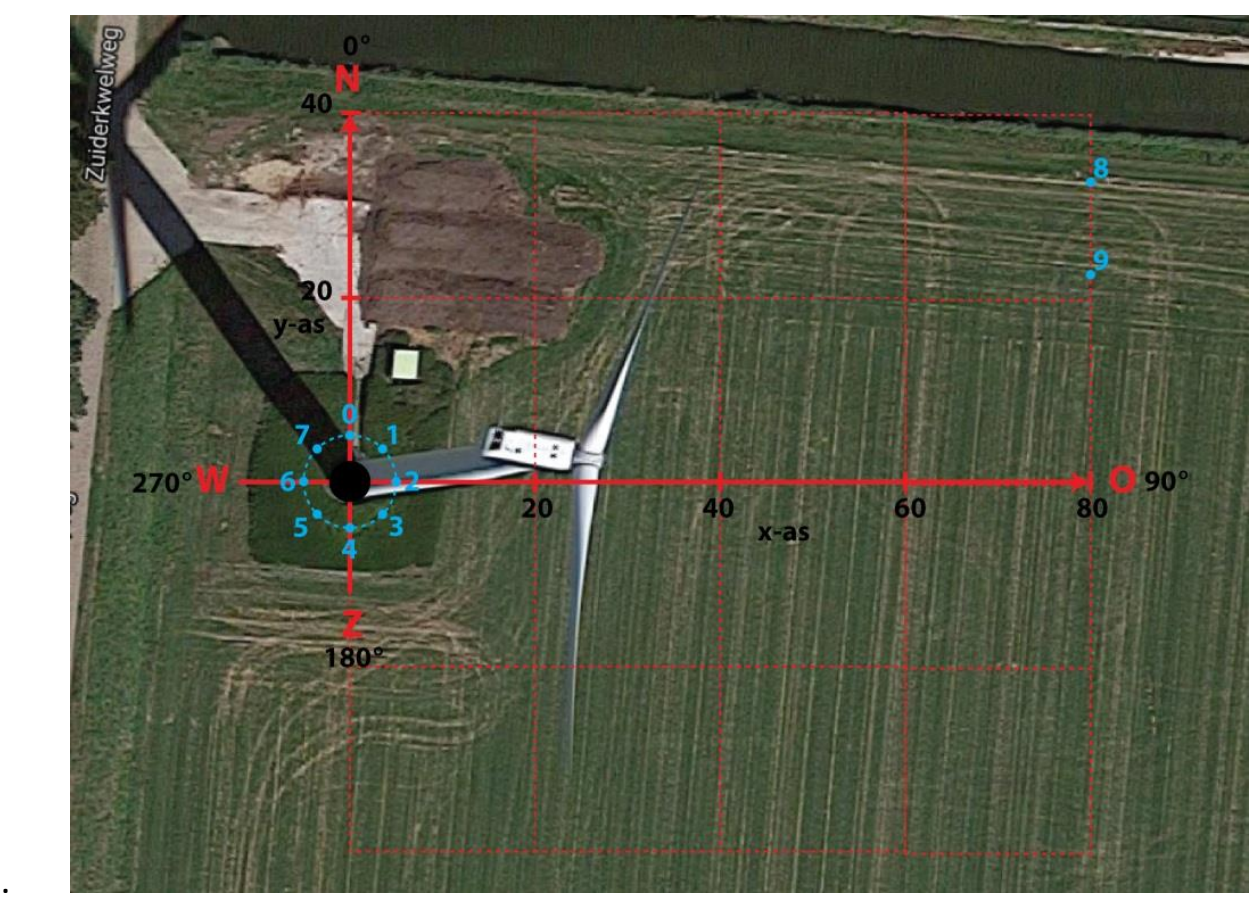

6. Figure camera position 0-7 and $5(b))$.

7. [alternative setup] A horizontal view where the two cameras were placed at $\pm 80 \mathrm{~m}$ from the wind turbine with $\pm 8-9 \mathrm{~m}$ distance (stereo base) between both cameras (see

8.

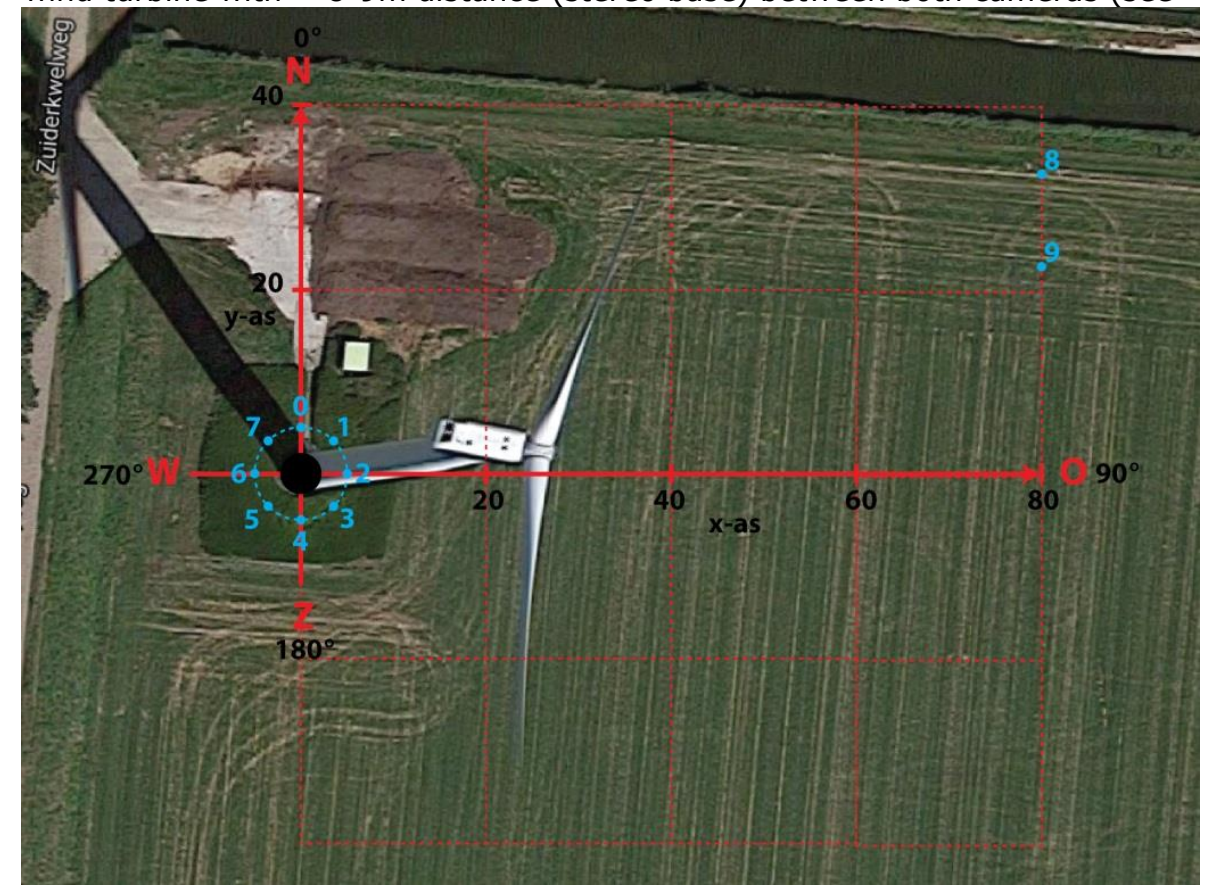

9. Figure camera position 8-9 and Figure a).

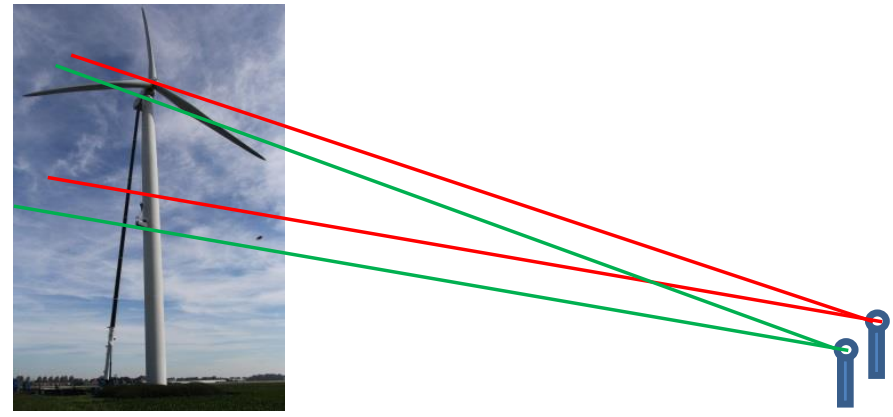

(a)

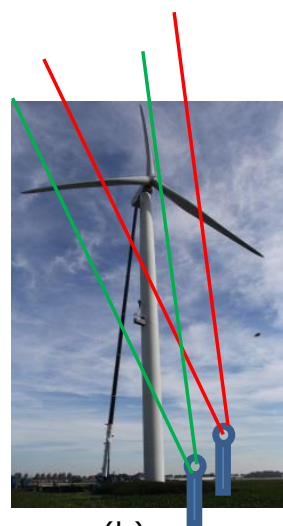

(b) 
Figure 5: Stereo setup. (a) shows the horizontal stereo setup where the two cameras are placed $80 \mathrm{~m}$ from the wind turbine facing towards the wind turbine. (b) shows the vertical stereo setup where the two cameras are placed near the wind turbine and facing upwards along the wind turbine.

During the recording nights most bat activity occurred at lower levels and only a few bats were recorded at nacelle height. In order to collect usable data, we therefore used the horizontal setup to collect the data for the reconstruction of the 3D flight paths.

\section{$2.4 \quad$ Monitoring effort}

The bat detector has been in operation from 25 August until 1 December 2016 between 15:00 - 8:00 UTC. The stereo camera-set was tested:

- 25 August 19:00 - 22:00 UTC

- 26 August 19:00 - 22:00 UTC

- 27 August 19:00 - 22:00 UTC

- 30 August 18:00 - 22:00 UTC

- 31 August 18:00 - 22:00 UTC

- 7 September 18:00 - 22:00 UTC

- 8 September 18:00 - 22:00 UTC

- 13 September 19:00 - 14 September 6:00 UTC

- 14 September 19:00 - 15 September 6:00 UTC

\subsection{Comparison of acoustic and flight path data}

In order to get insight in the performance of both systems we compared a flight track as determined by the stereo camera set-up with the acoustic measurements by the bat detector configuration.

The results are visualized by an animation application developed in $\mathrm{R}$. 


\section{Design of the equipment}

\section{$3.1 \quad$ Acoustic monitoring}

Several functional requirements were formulated before the equipment was selected.

1. The immediate surroundings of the wind turbine should be monitored acoustically as completely as possible.

2. The recordings at different locations at/near the wind turbine should be synchronized in time.

3. Weatherproof (storm, rain, frost)

4. No interference with the operating systems of the wind turbine.

5. Remote access to retrieve the monitoring data, monitor the performance of the equipment and adjust the settings if necessary.

6. Suitable for automated identification/classification of bat calls.

Therefore, it is necessary to apply multiple (as many as possible) ultrasonic microphones (requirement 1) which are connected to the same recorder, or apply multiple individual bat detectors which are synchronized in time (requirement 2). The ultrasonic microphones should be built in waterproof boxes as we were not allowed to drill holes in the wind turbine. The microphones should be heated to protect them from frost and for a quick recovery of the microphone sensitivity after rain. In addition, the microphone boxes and cables should be fixed tightly to the wind turbine in case of much wind (requirement 3).

A stand-alone computer should be used to run the software necessary to control the bat detector equipment (requirement 4) in order to avoid interference with the controlling hardware of the wind turbine. The computer should be able to access the detector through a network (requirement 5). The monitoring data should be automatically processed; this means that 'noise' recordings and microphone calibration test signals should be filtered out, and bat calls need to be identified automatically.

As it is technically complicated to synchronize multiple individual bat detectors, the only realistic option is a recorder with multiple channels. Therefore we selected a bat detector from Avisoft Bioacoustics, as this is the only supplier who produces multiple channel bat detectors. In order to maximise the monitoring area around the wind turbine, we chose a 12 channel recorder (the maximum number of channels available). We selected the FG-DT50 ultrasonic microphone, as these are specifically designed for bat monitoring at wind turbines. This type of microphone has a remotecontrolled reference signal generator and USB-powered heating. The microphones were embedded in waterproof boxes and placed in four different directions at three different heights (5, $35 \& 65$ meter) at the turbine tower. It was not possible to install microphones at the nacelle or in the blades. XLR microphone extension cables and heating wires were used to connect the microphones with the Utrasound gate detector which was placed in the turbine tower with the PC.

\subsection{Stereo configuration}

\subsubsection{Camera characteristics}

Several camera characteristics are important to collect footage at night and to determine 3D trajectories, these include resolution, frame rate and thermal sensitivity.

The resolution of the camera defines the amount of detail a camera image can capture, i.e. at what size and distance objects are still visible. A typical resolution for LongWave InfraRed (LWIR) cameras is $320 \times 240$ or $640 \times 480$. 
The frame rate defines the temporal resolution. The higher the frame rate, the more temporal resolution the recordings have. This means that a high frame rate can be used to show detailed and sharp images of moving objects that would otherwise be a blur. High frame rates are typically used for slow motion effects. The best frame rate for this application is determined by the resolution needed for the 3D path.

Thermal sensitivity is the ability of the camera to distinguish objects in a scene with little temperature differences between the objects. This is indicated as NETD: Noise Equivalent Temperature Difference. NETD changes with the temperature of an object, as the object temperature increases, the NETD decreases (better sensitivity).

The cameras are used in a stereo configuration, hence both the left and the right camera should capture an image at the same time.

We did not select camera's specifically for this study as two AXIS Q1932-E thermal cameras with a resolution of $640 \times 480$ and a frame rate of $30 \mathrm{~Hz}$ were already available.

\subsubsection{Synchronisation}

To be able to calculate 3D trajectories using stereovision, the stereo set must be synchronised. The timestamp of the used cameras has a resolution of $1 / 100$ seconds (Figure 6), which is accurate enough to have a unique timestamp in each video frame at the camera's maximum frame rate of 30 frames per seconds. Because the actual time between frames is 0.033 seconds $(3.3 / 100$ st second) the actual timestamp is rounded to the nearest $1 / 100$ st second.

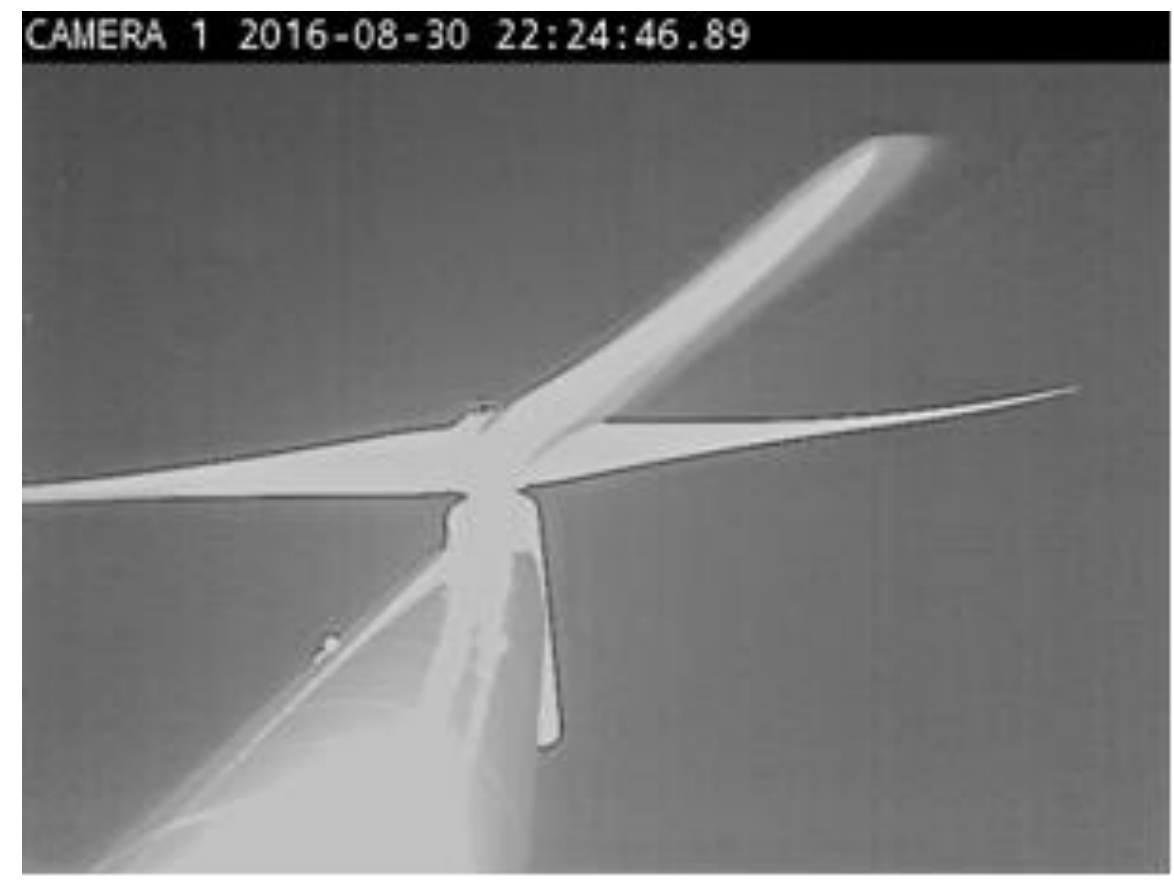

Figure 6: Camera image with timestamp. 


\section{2 .3}

For best stereovision accuracy at large distance, the distance between cameras should be as large as possible. Because the intended use of bat tracking is on an offshore wind turbine, the maximum distance between the cameras is about $10 \mathrm{~m}$. Stereovision is only possible when an object of interest is visible in both camera images. Therefore the field of view of both cameras, should overlap as much as possible at the object distance of interest. This can be achieved by rotating the cameras slightly towards each other, see Figure.

\section{In}

Figure an alternative converging stereovision setup is shown. The distance between the camera's is $50 \mathrm{~m}$. The advantage of this setup is a better accuracy. The disadvantage is a smaller overlapping area that starts at a greater height.

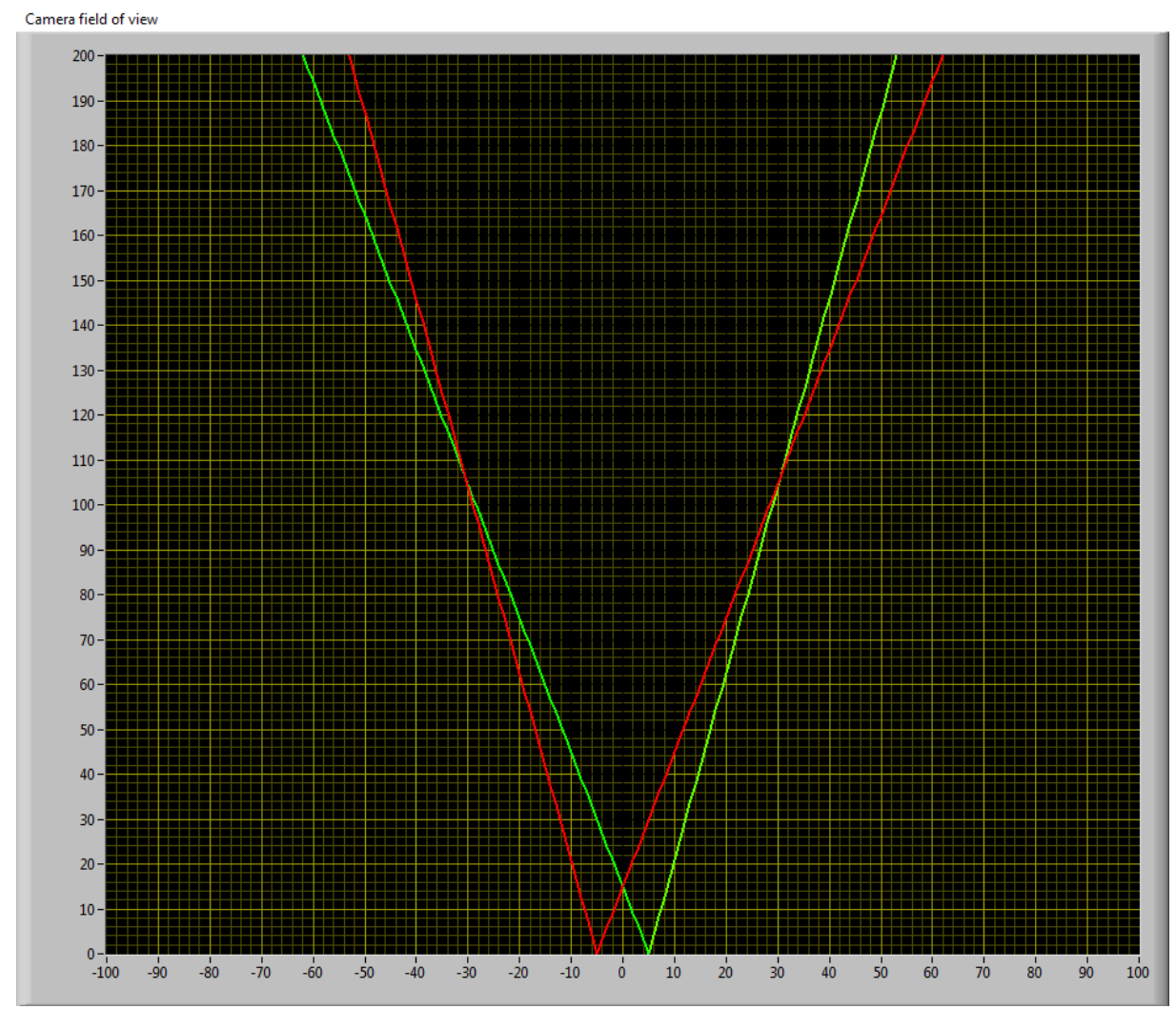

Figure 7: Camera field of view (FOV) for AXIS Q1932-E camera with $19 \mathrm{~mm}$ lens. The cameras base distance is $10 \mathrm{~m}$. Stereovision is possible in the dark coloured area. The FOVs of the converging left-sided and right-sided cameras are depicted as red and green lines respectively. 


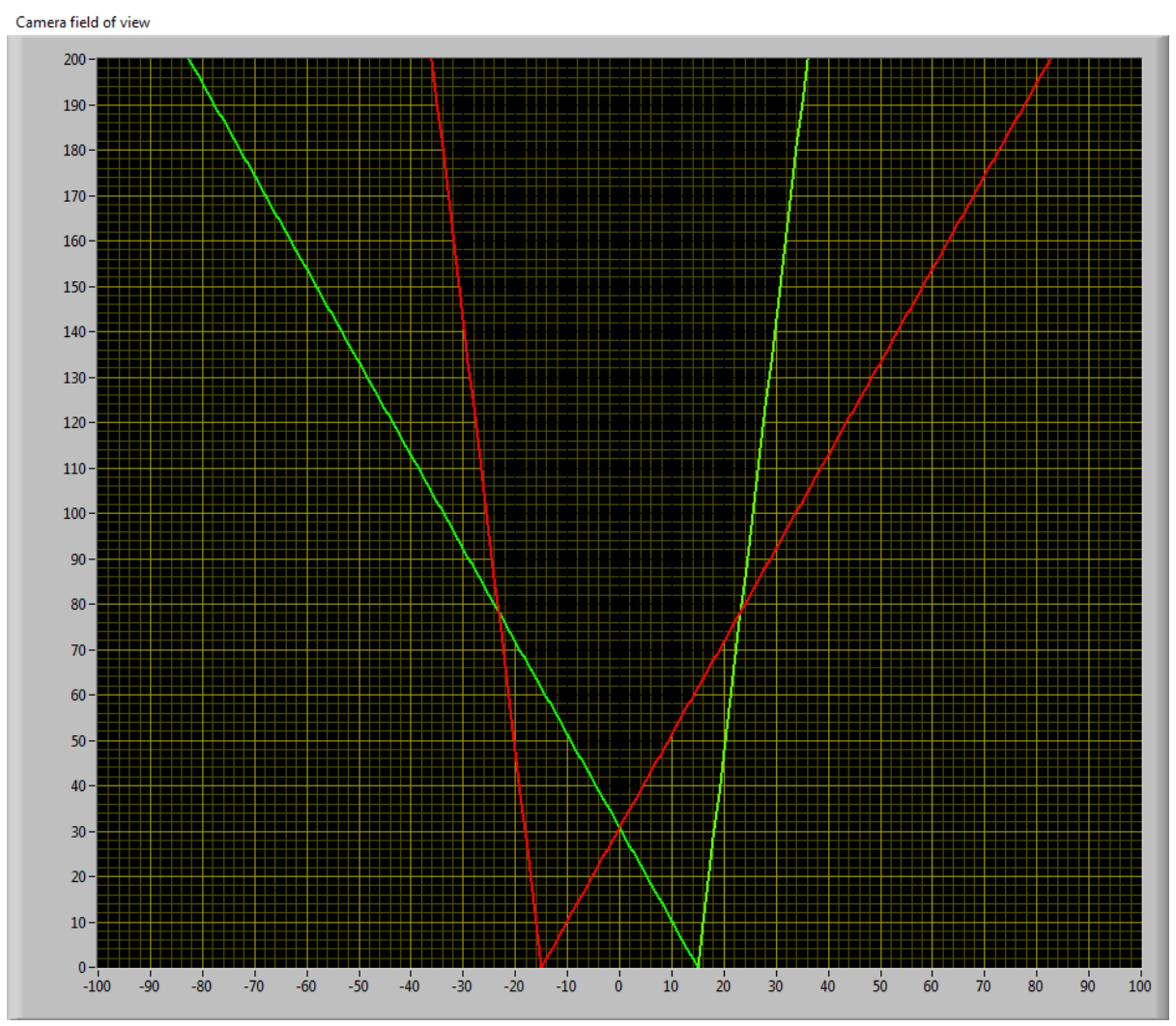

Figure 8: The cameras field of views (FOVs) with a camera base distance of 50m.

\subsubsection{Accuracy (horizontal position)}

The accuracy of the localization of an object in a horizontal plane at a certain height is directly related to the camera resolution at the height of the horizontal plane. The resolution is defined by the distance represented by one pixel at a certain height (see Figure ).

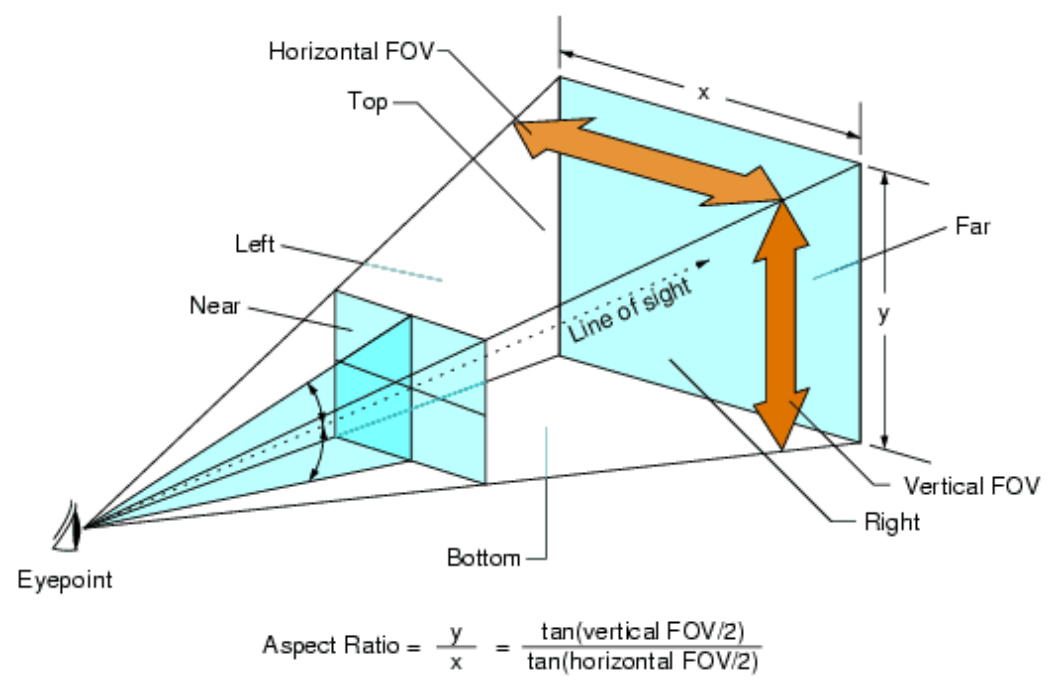

Figure 9: Accuracy in horizontal position.

Because at larger distances a larger area maps on the same number of pixels the resolution is inverse proportional to the distance. The resolution is furthermore dependent on the opening angle of the camera/lens. Objects in an image can be localized with one pixel accuracy. The accuracy for the 
localization can be estimated at the distance represented by one pixel at the distance of the object from the camera. This distance can be calculated with Equation 1.

$$
D=\frac{(2)}{D} \quad \text { Equation } 1
$$

Where:

$\mathrm{D}=$ distance represented by one pixel

$\alpha=$ opening angle of the camera/lens

$\mathrm{P}=$ number of pixels

For the AXIS Q1932-E camera (640 pixels, opening angle $32^{\circ}$ ) the accuracy is plotted in

Figure .

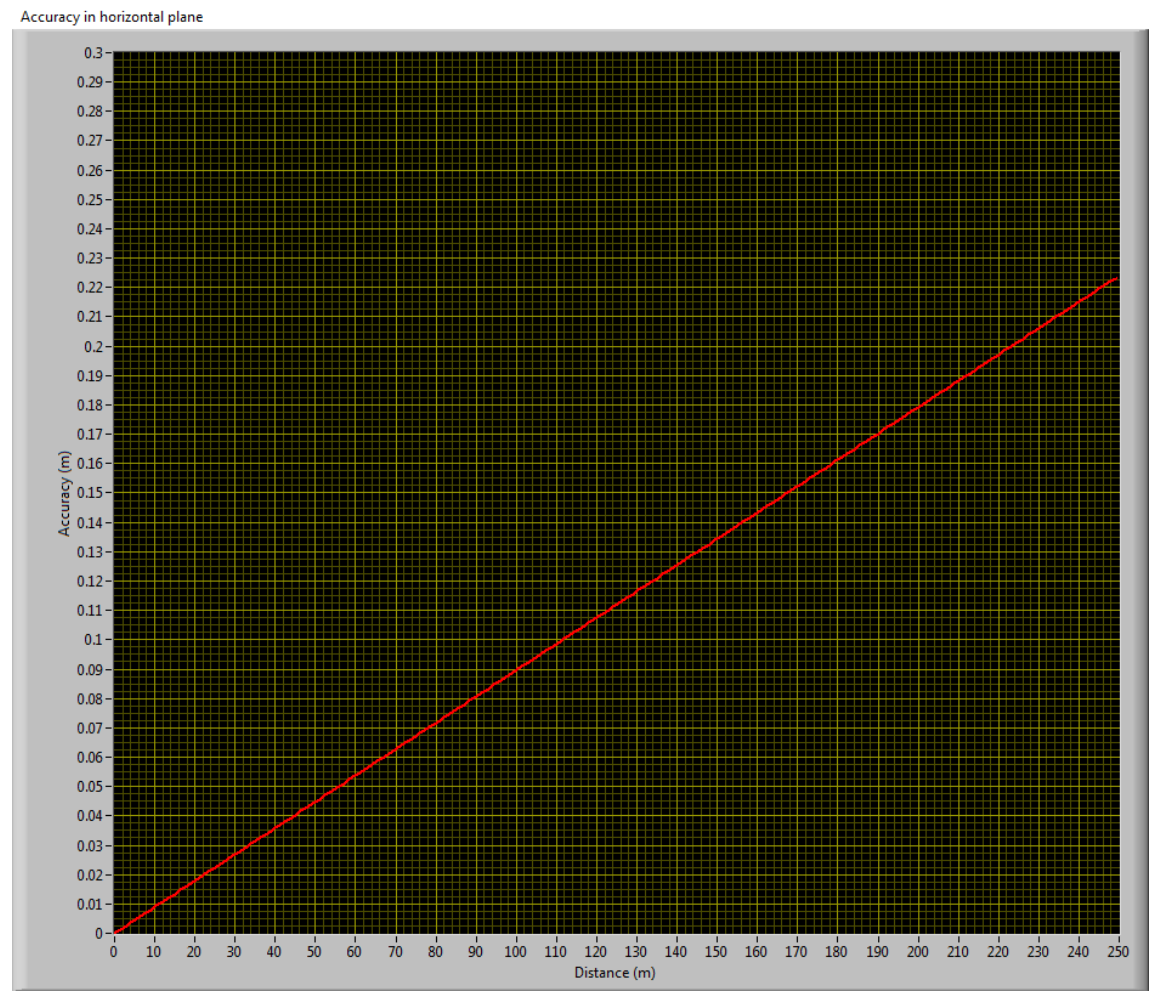

Figure 10: Horizontal accuracy for the AXIS Q1932-E camera.

\subsubsection{Accuracy (distance)}

Besides the accuracy of the position in the horizontal plane the accuracy in the $Z$ direction (height) can be calculated. Like the accuracy in the horizontal plane the accuracy in the $Z$ direction depends on the distance from the camera, but is also highly dependent on the distance between the camera's. A larger distance (baseline) between the camera's results in a higher accuracy in the $Z$ direction. The object is projected at a certain position on the sensors of both camera's. The disparity is the distance between two corresponding points in the left and right image of a stereo pair (Figure ). 


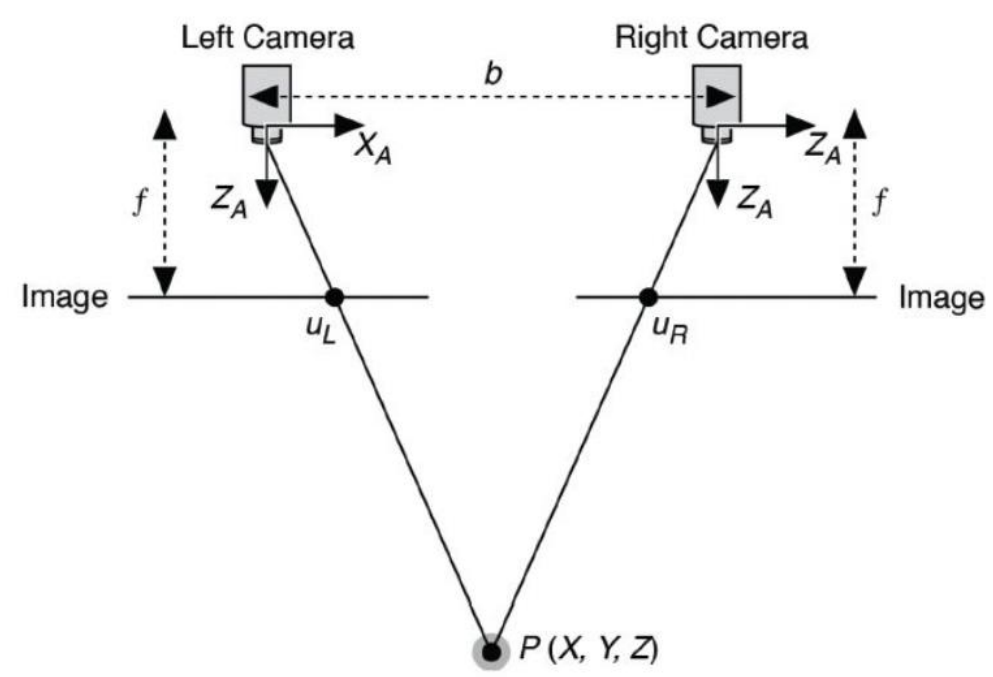

Figure 11: Layout of the disparity in the stereo image pair.

The distance of an object from the camera's ( $Z$ ) can be calculated using Equation 2 .

$$
\mathrm{Z}=\mathrm{f} * \frac{\mathrm{b}}{\mathrm{d}}
$$

Equation 2

Where:

$Z$ = distance

$f=$ focal length

$\mathrm{b}=$ baseline

$\mathrm{d}=$ disparity

The disparity is a quantized integer value because it is derived from a difference in number of pixels on the left and right camera sensors. To calculate the accuracy in Z direction we assume the disparity will be maximal one pixel off. This leads to Equation 3 for calculation of the accuracy.

$$
\text { Err }=Z-\frac{1}{\frac{1}{z}+\frac{d}{f \cdot b}}
$$

Equation 3

Because the accuracy decreases with the distance and is highly dependent on the baseline, the accuracy for several baseline distances is plotted in a graph (

Figure ). 


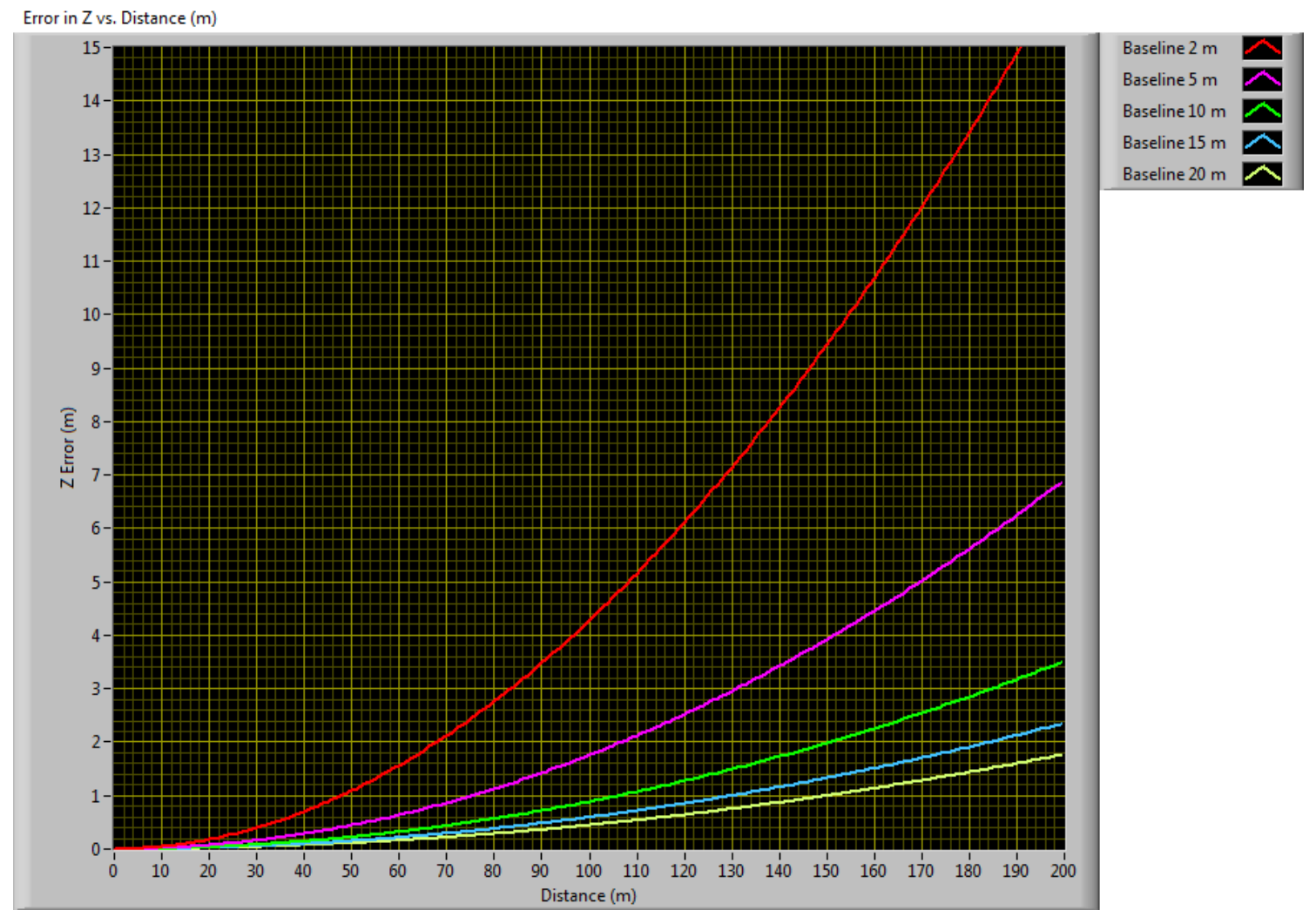

Figure 12: On the $x$-axis the distance in meters versus the vertical accuracy (Z-error) on the $y$-axis.

\subsubsection{Accuracy (timing)}

Every frame of the video streams of both camera's has a timestamp. Because the recordings cannot be started on both camera's at the same time, individual frames of both camera's will likely not have the same timestamp. Every 0.033 second a new frame is made by both camera's. The maximal time difference between two best matching frames is 0.02 seconds $(0.033 / 2$ rounded up to the next $1 / 100$ st seconds). The time difference can be related to an inaccuracy in the calculated 3D position given a certain speed. At a speed of $36 \mathrm{~km} / \mathrm{h}(10 \mathrm{~m} / \mathrm{s})$, a distance of $0.2 \mathrm{~m}$ is travelled in 0.02 seconds, so the maximum inaccuracy due to timestamp difference is $0.2 \mathrm{~m}$.

\subsubsection{Calibration}

\subsubsection{Intrinsic camera calibration}

Due to misalignments of the sensor chip and deformations in the lens, a camera image can have several distortions. We can correct for these distortions with an intrinsic camera calibration. The first type of distortion is the radial distortion caused by the lens. The correction for this can be captured by the following formulas:

$$
\begin{aligned}
& u^{\prime}=u\left(1+k_{1} r^{2}+k_{2} r^{4}+k_{3} r^{6}\right) \\
& v^{\prime}=v\left(1+k_{1} r^{2}+k_{2} r^{4}+k_{3} r^{6}\right)
\end{aligned}
$$

where $(u, v)$ are the original pixel coordinates and $\left(u^{\prime}, v^{\prime}\right)$ the corresponding coordinates in the corrected image. 
Tangential distortion occurs because the image taking lenses are not perfectly parallel to the imaging plane. It can be corrected via the formulas:

$$
\begin{aligned}
& \left(u^{\prime}=u+\left(2 p_{1} u v+p_{2}\left(r^{2}+2 u^{2}\right)\right)\right. \\
& v^{\prime}=v+\left(p_{1}\left(r^{2}+2 v^{2}\right)+2 p_{2} u v\right)
\end{aligned}
$$

This gives the following distortion parameters: $\left(k_{1} k_{2} k_{3} p_{1} p_{2}\right)$.

As we want to determine the 3D trajectories of the bats, we furthermore need to establish how points in the world $(X, Y, Z)$ map to image coordinates. This relationship involves the focal lengths of the camera, $\left(f_{x^{\prime}} f_{v}\right)$ and the principle point $\left(c_{x^{\prime}} c_{v}\right)$ :

$$
\begin{gathered}
{\left[\begin{array}{l}
x \\
y \\
x
\end{array}\right]=K\left[\begin{array}{l}
X \\
Y \\
Z
\end{array}\right]=\left[\begin{array}{ccc}
f_{x} & 0 & c_{x} \\
0 & f_{y} & c_{y} \\
0 & 0 & 1
\end{array}\right]\left[\begin{array}{l}
X \\
Y \\
Z
\end{array}\right]} \\
u=\frac{x}{w}, v=\frac{y}{w}
\end{gathered}
$$

Where $\mathrm{K}$ is the camera matrix.

Both the distortion parameters and the camera matrix, the so-called intrinsic parameters, can be estimated in a camera calibration procedure. This procedure requires a large number of images taken from a calibration pattern at different positions and orientation.

Figure3 shows a few examples. Software has been written to detect the calibration pattern in the images. The image coordinates of the chess-board corners combined with the real-world dimensions of the pattern are used to estimate the intrinsic parameters using the method described in Zhang (1998). The method estimates the parameters by minimizing the re-projection error.
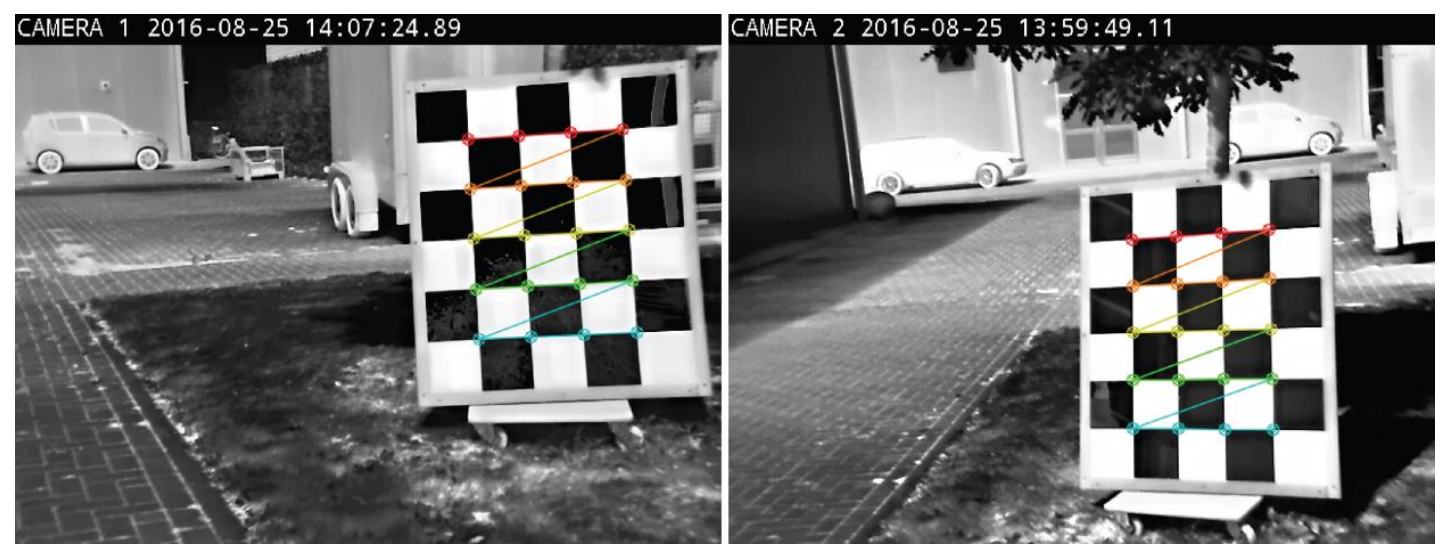

Figure 13: A few examples of the calibration pattern recorded by the long-wave infrared camera. The detection of the chess-board corners are drawn on top of the raw camera image.

\subsubsection{Stereo-camera calibration}

There are two methods for stereo-camera calibration. The first is the standard calibration technique using reference points with known 3D world coordinates, for instance when using a chess board as mentioned before. The other method does not rely on reference points with known 3D world coordinates, but instead on corresponding points in the left and right images. 
The latter method, which was used by us, is based on epipolar geometry (Hartley \& Zisserman 2003): for a specific point in one of the stereo images, the corresponding point in the other image can be found somewhere on a line, the epipolar line. The relationship between points in one image and the epipolar lines in the other image is captured in the fundamental matrix, $F$. This matrix has the following property:

$$
{ }^{X} \text { right }^{F X} \text { left }=0
$$

The essential matrix, containing information about the translation and rotation of the second camera with respect to the first, can be calculated from the fundamental matrix and the camera matrices of left and right image:

$$
E=K_{\text {right }}^{T} F K_{\text {left }}
$$

The transformation, $t$, and rotation, $\mathrm{R}$, of the right camera with respect to the left can be calculated from the essential matrix with Singular Value Decomposition and the projection matrices of the left and right images can then be calculated as also explained in section 3.2.4.1.

Using these projection matrices for 3D reconstruction will be correct up to a scaling factor, as no information about the 3D position of points is provided. The coordinates will also be with respect to the left camera. If needed, the 3D reconstruction can be put in world coordinates, using a minimum of three $3 \mathrm{D}$ reference points.

\subsubsection{Tracking moving objects}

Typically, an object will be visible in multiple consecutive frames. We therefore need to match the objects in $O_{t}$ at time ${ }_{t}$ with the objects in $O_{t+1}$ at time $t+1$. To do this, we make use of a combination of Kalman filters (Kalman 1960) and the Hungarian Algorithm (Kuhn 1955). The position of every object over time is tracked by a Kalman filter. The Kalman filter is a probabilistic Bayesian filter, used to estimate the position of an object given a series of noisy measurements observed over time (Russel \& Norvig 2010). The position of an object is represented, probabilistically modelled as a Gaussian distribution $N\left(\hat{x}_{t}, \sigma_{t}^{2}\right)$. The mean is updated based on the previous estimation, $\hat{x}_{t-1}$, the motion vector, $u_{t}$ and a new observation of the object, $z_{t}$ :

$$
\hat{x_{t}}=\hat{x}_{t-1}+u_{t}+K_{t}\left(z_{t}-\hat{x}_{t-1}-u_{t}\right)
$$

The uncertainty is update as:

$$
\sigma_{t}^{2}=\sigma_{t-1}^{2}-K_{t} \sigma_{t}^{2}
$$

where $K_{t}$ is the Kalman gain:

$$
K_{t}=\frac{\sigma_{t-1}^{2}+\sigma_{u}^{2}}{\sigma_{t-1}^{2}+\sigma_{u}^{2}+\sigma_{u}^{2}}
$$

with $\sigma_{t}^{2}$ being the uncertainty in the observation and $\sigma_{u}^{2}$ the uncertainty in the motion vector. Intuitively, the position of the object is updated with the motion vector and the uncertainty of the estimation grows by applying the motion vector and reduces when a new observation is made.

For tracking the moving objects, we use the Kalman filters to predict the position $\hat{x}_{t-1}^{1}$ of all objects in the next frame:

$$
\hat{x}_{t+1}^{i}=\hat{x}_{t}^{i}+u_{t}^{i}
$$

This prediction is then compared to the observed object positions in the next frame. As we have $n$ predictions based on the current frame and $m$ observations in the next frame, the question arises 
which prediction belongs to which observation. This assignment problem is solved using the Hungarian Algorithm (Munkres 1957). Based on the distances between all predictions and all observations, the algorithm makes an optimal assignment, minimizing the overall distance.

The 2D trajectories are detected separately in the left and right camera images. Examples are shown in Figure4. Important to note is that many of the trajectories are caused by low-flying insects that were in front of the cameras. The similar looking trajectories (in the left and right camera images) are of bats and the other trajectories mainly of insects.

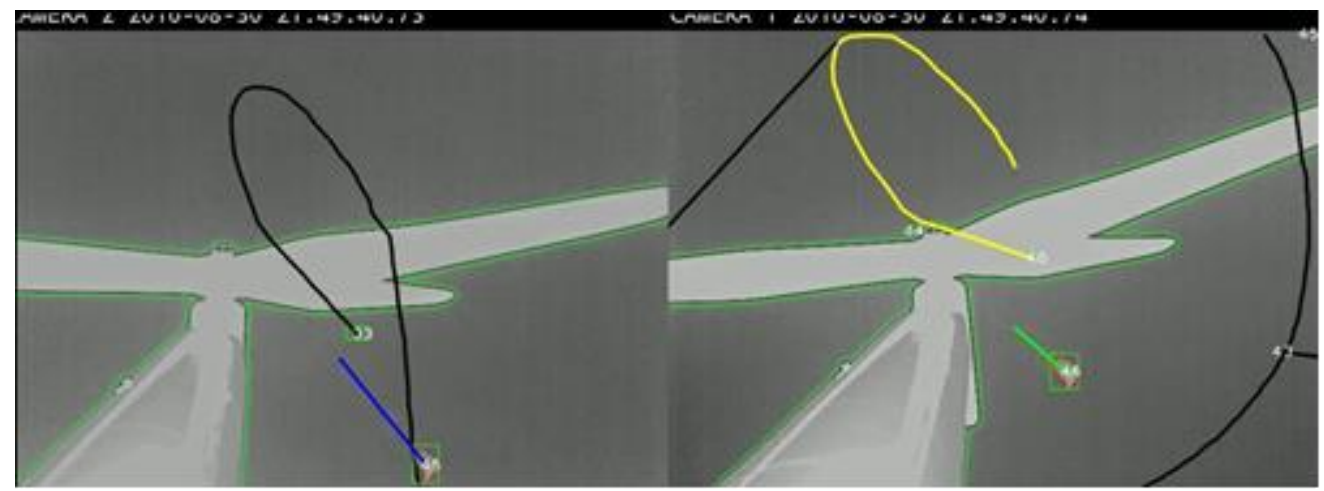

(a)

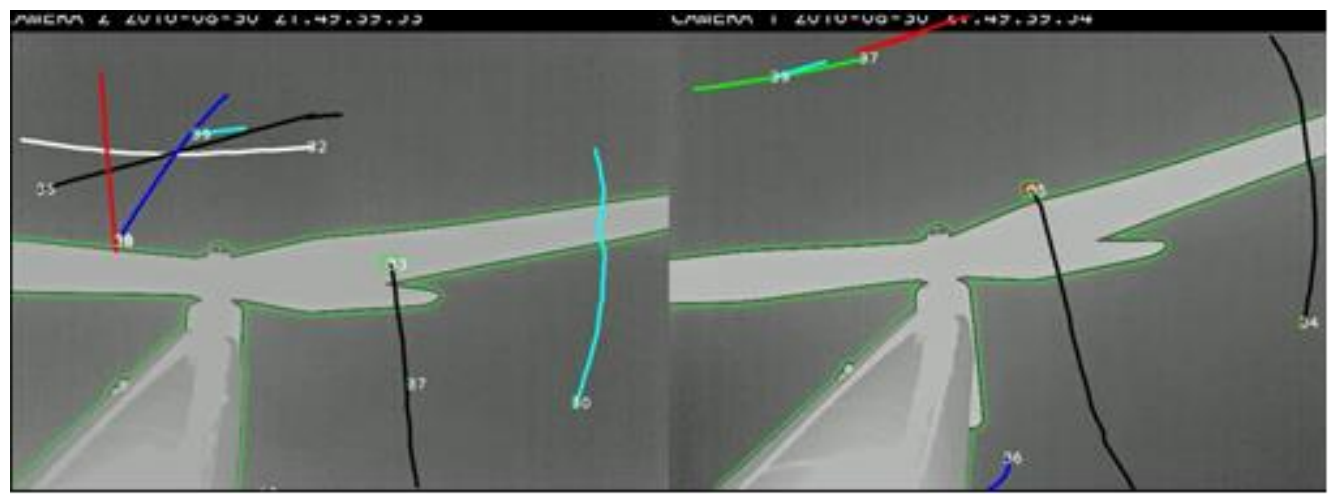

(b)

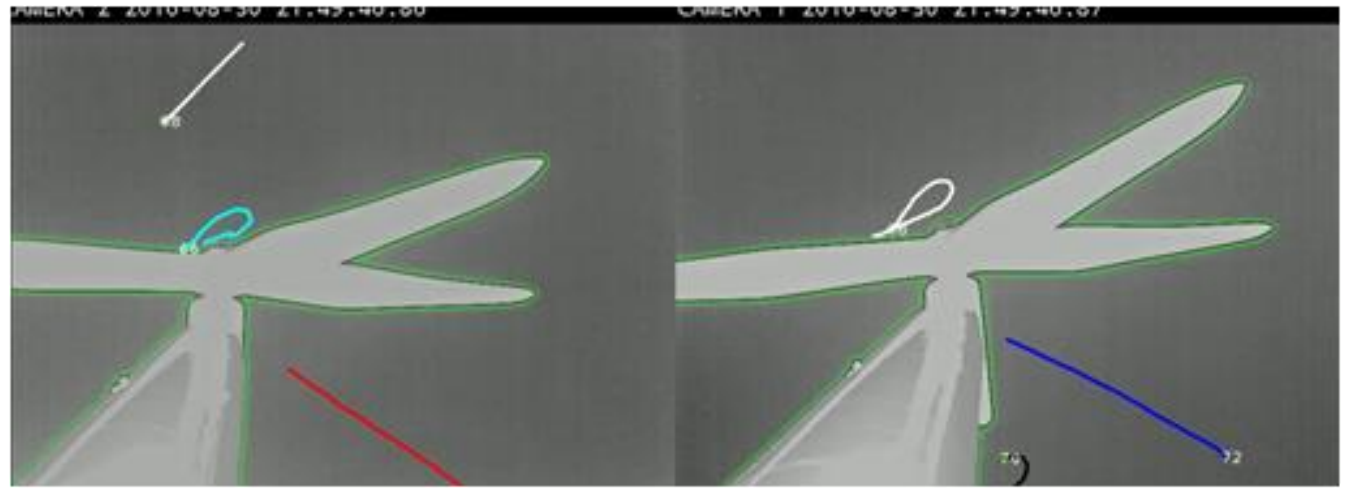

(c)

Figure 14: Identified 2D trajectories in the left and the right camera image. The thin green outline marks the detected wind turbine. Note that some of the trajectories are of bats, but many others of insects flying at close distance. 
If we have two corresponding points in the left and right image, the 3D position of the point can be determined using triangulation based on the position of the points in the images, $\mathrm{X}_{\text {left }}$ and $X_{\text {right }}$, as well as both projection matrices, $P_{\text {left }}$ and $P_{\text {right }}$

$x_{\text {world }}=\operatorname{triangulation}\left(X_{\text {left }}, X_{\text {right }} P_{\text {left }}, P_{\text {right }}\right)$

In the current version of the software, the detection of the position of the bats in the images is based on manual input, as the available budget in this phase of the project was not sufficient to develop a fully automatic procedure. Developing such a procedure was more complicated than expected, mainly due to the high amount of insects that are visible in the images, as can be appreciated from Figure. The challenge in the next phase is to automatically match the right trajectory in both video frames. 


\section{$4 \quad$ Results}

\subsection{Bat detector}

\subsubsection{Performance}

The bat detector configuration was installed 25 August 2016. Microphones and cables were attached to the mast with magnets. In addition the microphones at 35 and $65 \mathrm{~m}$ were secured with a strap around the mast. Mechanically, it performed well until the end of the monitoring season (1 December 2016). However, during severe winter storms after that day, two of the lower microphones (which were not secured by straps) and the cables attached ended up a few meters further away on the mast and were turned upside-down. Acoustically the bat detector performed well during the entire monitoring season. However, on one occasion it was noted that the processing capacity of the PC was not sufficient to cope with a high number of recordings caused by multiple bats flying around the mast.

\subsubsection{Number of recordings}

A total of 173.496 files were recorded by the bat detector between 25 August and 1 December 2016. It is estimated that c. $80 \%$ of the recordings are bat calls and c $20 \%$ concern 'noise' and calibration signals. $75 \%$ was recorded by the microphones at a height of $5 \mathrm{~m}, 17 \%$ at $35 \mathrm{~m}$ and $8 \%$ at $65 \mathrm{~m}$.

\subsubsection{Automated classification of calls}

Manual identification using the criteria by Barataud (2016) of the 96 recordings in the sample resulted in 1 recording of common noctule, 4 Nyctaloids (includes the genera Nyctalus, Vespertilio and Eptesicus), 23 Nathusius' pipistrelles, 63 common pipistrelles, 5 Pipistrelloid (Pipistrellus spec), 3 calibration signals and 7 'noise' recordings.

The 96 recordings in the sample contained 1484 individual call elements which were identified automatically by a combination of acoustic properties (table 2 ). A total of $67 \%$ of the call elements were identified correctly, $22 \%$ inconclusive and $11 \%$ incorrect. Inconclusive means in this case not incorrect, e.g. Nathusius' or common pipistrelles which are identified as Pipistrelloid.

Table 2: Automated identification of 1484 call elements by a combination of acoustic properties. Green indicates a correct identification, orange an inconclusive identification and red an incorrect identification.

\begin{tabular}{|c|c|c|c|c|c|c|c|c|}
\hline Recording & $\begin{array}{l}\frac{\sigma}{0} \\
\frac{0}{\pi} \\
\stackrel{0}{0} \\
z\end{array}$ & 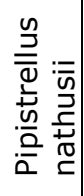 & 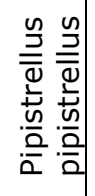 & $\begin{array}{l}\frac{\overline{0}}{0} \\
\overline{\overline{0}} \\
\frac{1}{4} \\
. \frac{n}{0} \\
\frac{0}{0}\end{array}$ & 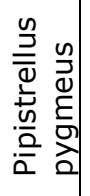 & $\begin{array}{l}0 \\
.0 \\
0 \\
z\end{array}$ & $\begin{array}{l}5 \\
3 \\
0 \\
\frac{5}{5} \\
5 \\
5\end{array}$ & $\begin{array}{l}\bar{\pi} \\
0 \\
0\end{array}$ \\
\hline Nyctalus noctula & 2 & & & & & & 1 & 3 \\
\hline Nyctaloid & 20 & & & & & 1 & 10 & 31 \\
\hline Pipistrellus nathusii & & 130 & 80 & 109 & 1 & & 16 & 336 \\
\hline Pipistrellus pipistrellus & & 1 & 723 & 54 & 30 & 4 & 34 & 846 \\
\hline Pipistrelloid & & 7 & 70 & 51 & 1 & & 2 & 131 \\
\hline Testsignal & & 5 & 41 & & & 17 & 4 & 67 \\
\hline Noise & & & & & & 69 & 1 & 70 \\
\hline Total & 22 & 66 & 914 & 167 & 32 & 91 & 68 & 1484 \\
\hline
\end{tabular}

Subsequently the same recordings were identified automatically by a cross correlation with reference calls (table 3). $67 \%$ of the call elements were identified correctly, $28 \%$ inconclusive and $5 \%$ incorrect. 
Table 3: Automated identification of 1484 call elements by cross correlation with reference calls. Green indicates a correct identification, orange an inconclusive identification and red an incorrect identification.

\begin{tabular}{|c|c|c|c|c|c|c|c|c|c|}
\hline Recording & 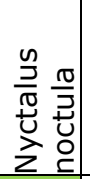 & 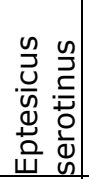 & 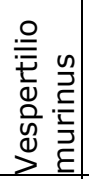 & 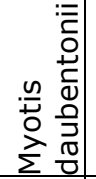 & 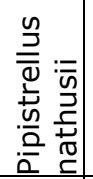 & 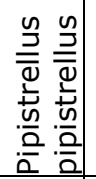 & $\begin{array}{l}0 \\
\frac{y}{0} \\
Z\end{array}$ & 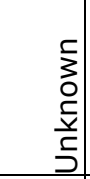 & Total \\
\hline Nyctalus noctula & 3 & & & & & & & & 3 \\
\hline Nyctaloid & 19 & 4 & 3 & & & & & 5 & 31 \\
\hline Pipistrellus nathusii & & & & 5 & 292 & 5 & & 34 & 336 \\
\hline Pipistrellus pipistrellus & & & & & 56 & 665 & & 125 & 846 \\
\hline Pipistrelloid & & & & & 63 & 56 & & 12 & 131 \\
\hline Testsignal & & & & & 3 & 1 & 8 & 55 & 67 \\
\hline Noise & & & & & & & 36 & 34 & 70 \\
\hline Total & 22 & 4 & 3 & 5 & 414 & 727 & 44 & 265 & 1484 \\
\hline
\end{tabular}

\subsection{Flight path visualisation}

Figure shows an example of a reconstructed 3D trajectory of a bat. The green points are the reconstructed calibration points, which are part of the post of the wind turbine, some points on the trees in the background and on some structures in front of the wind turbine (see

Figure for the camera images). The trajectory of the bat is depicted in red. In this case, the bat was close to the wind turbine and took a straight flight path towards the cameras in a diagonal line.
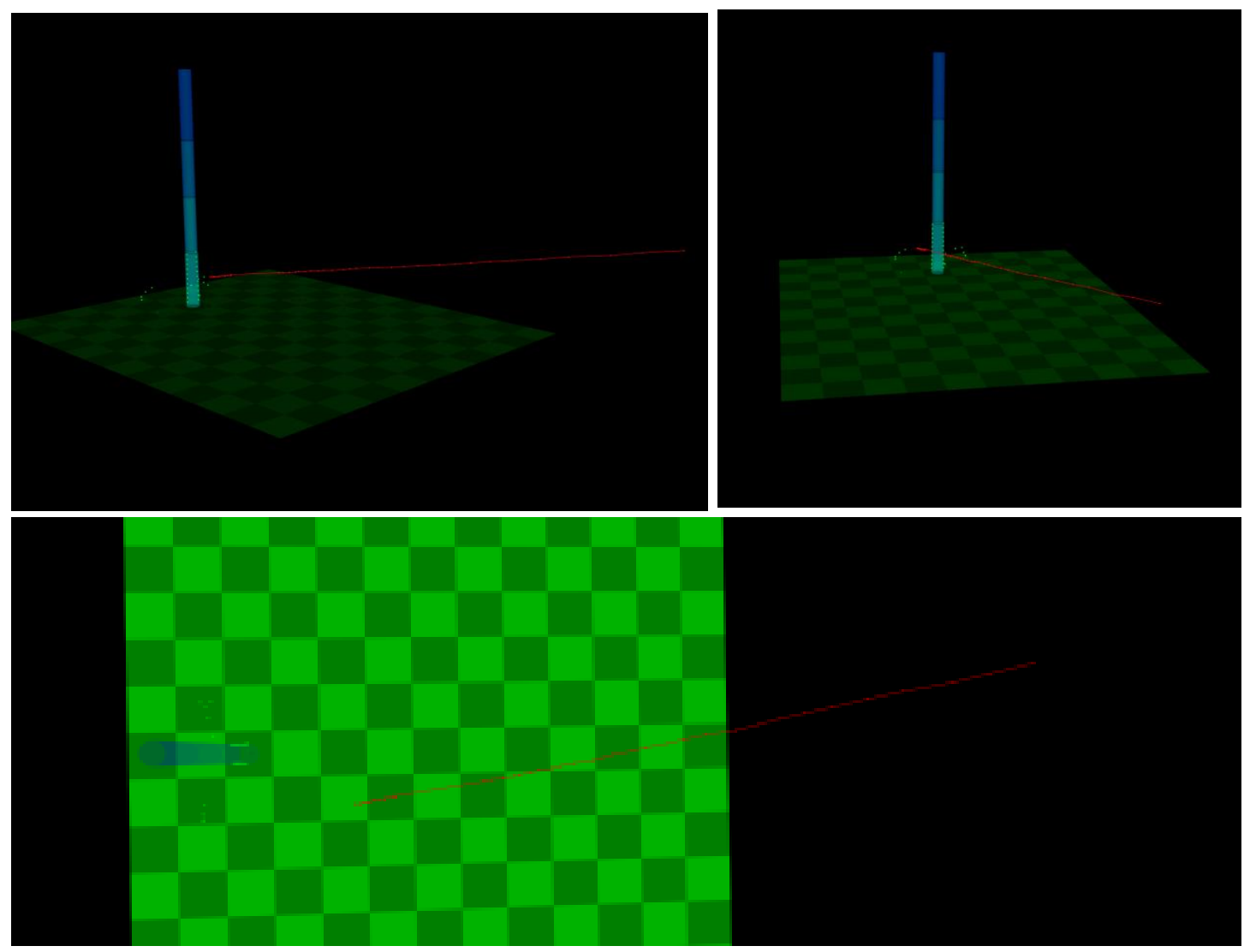

Figure 15: The 3D reconstruction of part of the wind turbine and the trajectory of a bat. The green points are 3D reconstructed calibration points. Red shows the bat's trajectory. Top left: frontal view, top right: diagonal view, bottom: top view. 
Figure shows two other examples of reconstructed paths. Here, you can clearly see that the bat is close to the wind turbine, hunting insects. In the image on the left, the bat is zigzagging around the pole, moving upwards. At an altitude of approximately 25 meters, it flies off. At the right, the bat approaches the wind turbine, makes a U-turn, and flies away from the wind turbine with high speed (approximately $50 \mathrm{~km} / \mathrm{h}$ ).

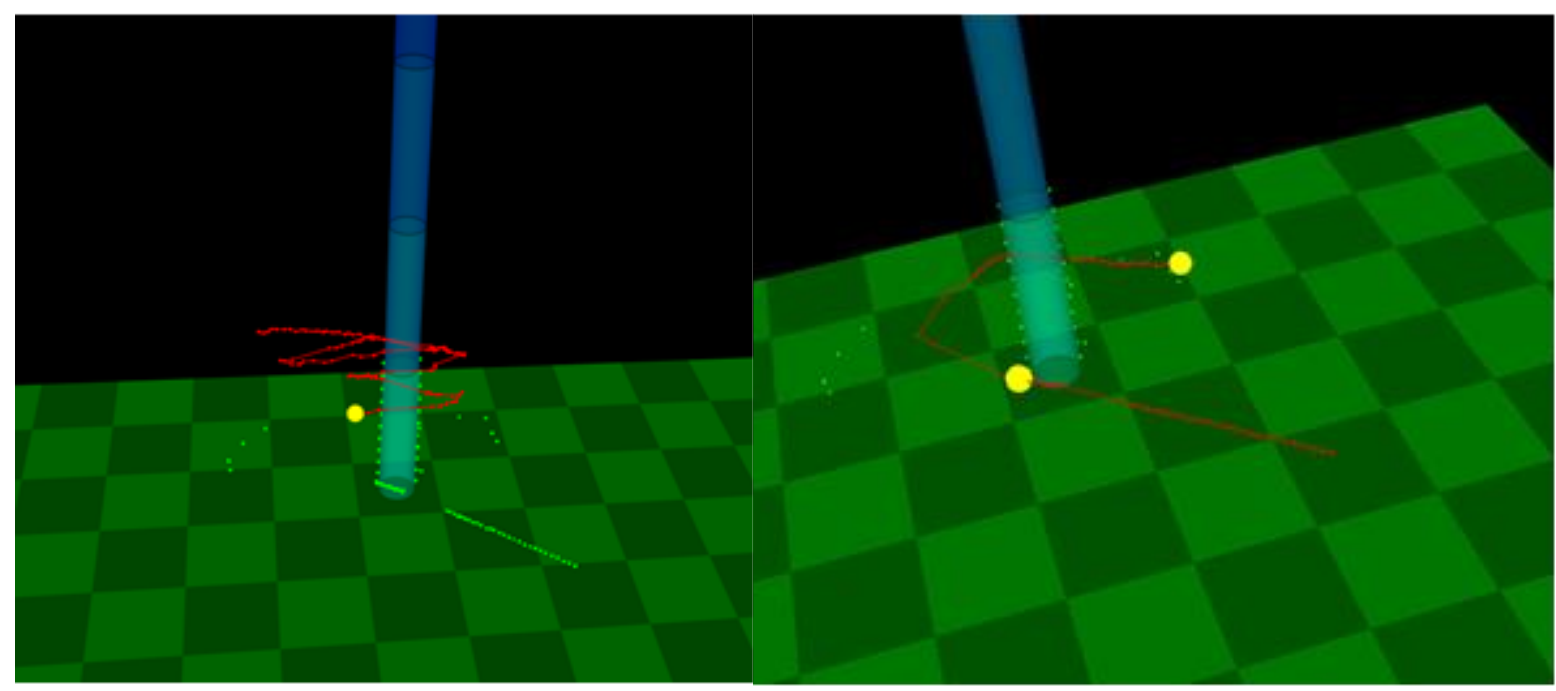

Figure 16: Two reconstructions of bat trajectories. Yellow ball is the starting point. Left: a bat that zigzags around the pole upwards. Right: a bat that approaches the wind turbine and then leaves the location on high speed.

\subsection{Comparison of flight path and measured acoustic activity}

We visualized the same trajectory as in Figure 16 (right) but also added the measured acoustic activity (Figure 17). When the bat approached the wind turbine, its sonar was recorded by three microphones simultaneously and two microphones were triggered when it passed the mast. Then it turned 90 degrees and flew away from the mast, resulting in one microphone receiving the sonar. Then it turned again 90 degrees and flew back and was detected by two different microphones. It seems that the measured $3 \mathrm{D}$ path matches with the measured acoustic activity (note that bat sonar is very directional and therefore bats can easily be missed when flying away from the microphone even though they are close, e.g. at 17.59:09 UTC). 

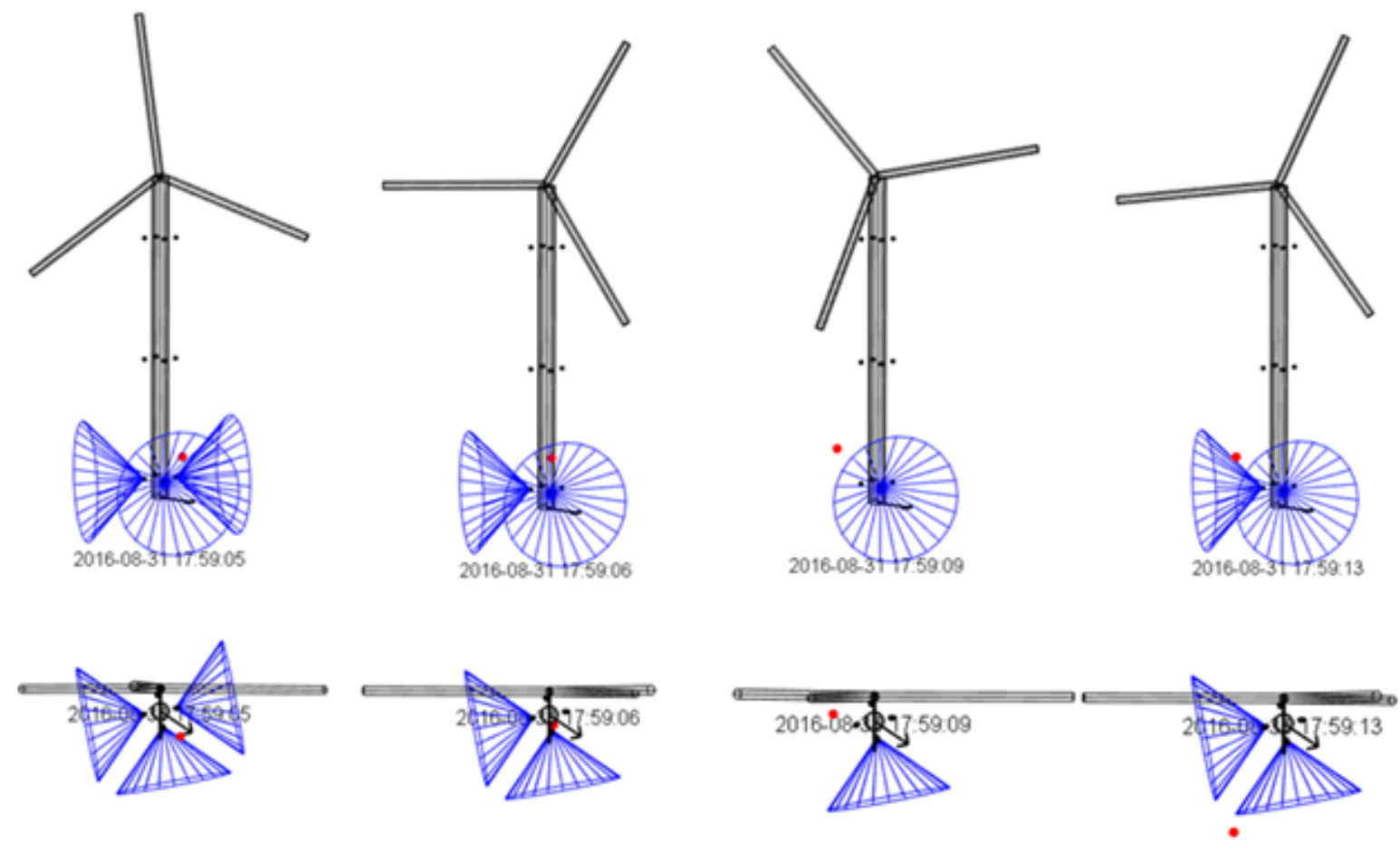

Figure 17: A passing bat (represented by the red dot) as determined by $3 D$ tracking and the measured acoustic activity at the same time. The arrow indicates north. 


\section{Discussion and Conclusions}

\section{$5.1 \quad$ Acoustic monitoring}

From the acoustic measurements during the monitoring period it can be concluded that the bat detector configurator:

- $\quad$ Performed well during the entire monitoring period

- Is able to monitor bat activity simultaneously at multiple heights in different directions.

- Mechanical improvements are necessary to secure the microphones and cables at the turbine.

- A more powerful PC should be applied to prevent an overload in case of high bat activity caused by multiple bats.

Much more bat activity was recorded than anticipated. A total of more than 170,000 recordings were obtained, on average almost 1800 per night. It was estimated that c. $80 \%$ concerned bats, the latter c. $20 \%$ being 'noise' or calibration signals. Most activity (75\%) was recorded at a height of $5 \mathrm{~m}$ above ground level, $17 \%$ at $35 \mathrm{~m}$ and $8 \%$ at $65 \mathrm{~m}$. The decrease of bat activity in relation to height is consistent with the findings of other studies, e.g. Behr et al. (2011) and Brinkmann et al. (2011).

It is not realistic to identify such an amount of recordings manually. Therefore, we investigated the feasibility of two methods for automated classification of bat calls, by acoustic parameters and by cross correlation with reference calls. Both methods resulted in $67 \%$ correct identifications, but the latter method performed better with respect to the number of incorrect identifications ( $5 \%$ against $11 \%$ ). It is likely that the results of both methods can be improved by incorporating more acoustic parameters as classification criteria and adding more reference calls respectively. Further improvements can probably be achieved if a probability is calculated based on the identifications of all individual call elements in one recording.

\subsection{Stereo configuration}

The scope of the conducted feasibility study was to detect bats at a height of $80 \mathrm{~m}$ around a wind turbine on land with a single stereo setup. From this study can be concluded:

1. The AXIS Q1932-E cameras with a resolution of $640 \times 480$ pixels and a $32^{\circ}$ opening angle are adequate to collect footage at a height of $40-120 \mathrm{~m}$.

- The theoretical accuracy to locate an object in the horizontal plane (the $x$ and y coordinates) on $80 \mathrm{~m}$ is $8.5 \mathrm{~cm}$. The horizontal accuracy decreases with increasing camera distance. For instance, for an object which is $250 \mathrm{~m}$ away from the camera the inaccuracy of the $\mathrm{x}$ and $\mathrm{y}$ coordinates is less than $27 \mathrm{~cm}$ (see Figure ).

- The used cameras allow little control of the user with respect to triggering, gain and contrast shutter time. This affects the detectability of bats (and birds), which eventually may result in an underestimate of the number of fatalities. Therefore, the detectability may be improved by using cameras that allow more control.

2. A stereo setup was successfully applied:

- The images of both cameras could be synchronized

- The intrinsic and extrinsic calibration are feasible

- $2 \mathrm{D}$ tracks can be detected in the left and the right camera stream

- The proof of concept to identify 3D tracks of moving objects is shown in this feasibility study. However, currently, manual input is needed and a full automatic procedure that selects the appropriate 3D bat tracks (and not the insects and/or clouds) needs to be developed. 
- $\quad$ The estimated $3 \mathrm{D}$ flight path is supported by the acoustic measurements. Because bat detector and stereo camera set are not synchronized, in time we cannot compare the measurements quantitatively yet.

The 3D bat paths give insight in the bat flight behavior around wind turbines and are likely to register collision and possibly even barotrauma events.

With only two cameras available, only a portion of the turbine can be covered. For full coverage of the rotor swept area, multiple cameras are needed. How many cameras are needed depends on: the dimensions of the turbine, the opening angle of the cameras used, the positioning of the cameras, the sensitivity of the camera, distances between the cameras and occlusions (e.g. the mast).

This setup might also be used to detect bird collisions; moderate size birds (black-headed gull Chroicocephalus ridibundus, waders) and big birds (geese) are clearly visible in the camera footage at night. 


\section{Recommendations}

The used stereo configuration and analysis methods are promising, but need further improvement so that reliable 3D paths can be derived automatically. The next step is to build a prototype with multiple stereo cameras (which can cover the entire rotor swept area) on land and prove the feasibility for a configuration on sea and use it for birds as well.

A multichannel bat detector must be used to measure the acoustic activity around the entire wind turbine. The measured acoustic activity can be used to assess the accuracy of the flight paths. They can also be used for species identification and to assess their behaviour, as foraging bats use different acoustic signals than bats passing by.

The algorithms for automated identification need to be developed further, as the best method currently identifies $5 \%$ of the call elements incorrect. For practical use we assume that an acceptable error rate should be well below $1 \%$.

The clock of all measurement equipment (cameras, batdetector and on the wind turbine) should be synchronized or connected to a shared network in order to obtain data with correct time stamps. 


\section{Quality Assurance}

Wageningen Marine Research utilises an ISO 9001:2008 certified quality management system (certificate number: 187378-2015-AQ-NLD-RvA). This certificate is valid until 15 September 2018. The organisation has been certified since 27 February 2001. The certification was issued by DNV Certification B.V. 


\section{References}

Bach, P., L. Bach \& K. Ekschmitt 2014. Bat activities and bat fatalities at different wind farms in Northwest Germany. Book of Abstracts XIIIth European Bat Research Symposium, Sibenik, Croatia.

Baerwald, E.F., G.H. D'Amours, B.J. Klug \& R.M.R. Barclay 2008. Barotrauma is a significant cause of bat fatalities at wind turbines. Current Biology 18: 695-696.

Barataud, M. 2016. Acoustic Ecology of European Bats: Species Identification, Study of Their Habitats and Foraging Behavior. University of Chicago Press, Chicago, Illinois, 352 pp. (cloth). ISBN: 987-285653-771-8.

Behr, O., R. Brinkmann, I. Niermann, and F. Korner-Nievergelt. Akustische Erfassung der Fledermausaktivit" at an Windenergieanlagen, volume 4, pages 177-286. Cuvillier Verlag, Göttingen, 2011.

Boshamer, J.P.C. \& J.P. Bekker 2008 Nathusius' pipistrelles (Pipistrellus nathusii) and other species of bats on offshore platforms in the Dutch sector of the North Sea. Lutra 51: 17-36.

Brinkmann, R., O. Behr, I. Niermann, \& M. Reich. Entwicklung von Methoden zur Untersuchung und Reduktion des Kollisionsrisikos von Flederm "ausen an Onshore-Windenergieanlagen, volume 4 of Umwelt und Raum. Cuvillier Verlag, Göttingen, 2011.

Cryan, P.M., P.M. Gorresen, C.D. Hein, M.R. Schirmacher, R.H. Diehl, M.M. Huso, D.T.S. Hayman, P.D. Fricker, F.J. Bonaccorso, D.H. Johnson, K. Heist \& D.C. Dalton 2014. Behavior of bats at wind turbines. www.pnas.org/cgi/doi/10.1073/pnas.1406672111.

Francis, C.M., P.D. Taylor \& Z.J. Crysler 2016. Motus Wildlife Tracking System: a novel approach for tracking small birds. BOU Proceedings - Birds in time and space: avian tracking and remote sensing. http://www.bou.org.uk/bouproc-net/tracking/poster-francis-etal.pdf

Proceedings of the BOU's 2015 Annual Conference | \#BOU2015. Birds in time and space: avian tracking and remote sensing.

Hartley, R. \& A. Zisserman 2003. Multiple View Geometry in Computer Vision (2 ${ }^{\text {nd }}$ edition). University Press, Cambridge. ISBN: 978-0-521-54051-3

Janssen, R., A.J. Haarsma \& S. Lagerveld 2016. Pilotonderzoek vleermuizen vangen en volgen over zee. IMARES, Report C038/16.

Jonge Poerink, B., S. Lagerveld \& H. Verdaat 2013. Pilot study bat activity in the Dutch offshore wind farms OWEZ and PAWP (2012). IMARES report C026/13.

Kalman, R.E. 1960. A New Approach to Linear Filtering and Prediction Problems. Transactions of the ASME--Journal of Basic Engineering, 82(Series D): 35-45.

Kays, R., S. Tilak, M. Crofoot, T. Fountain, D. Obando, A. Ortega, F. Kuemmeth, J. Mandel, G. Swenson, T. Lambert, B. Hirsch \& M. Wikelski 2011. Tracking animal location and activity with an automated radio telemetry system in a tropical rainforest. The Computer Journal, bxr072

Körner, F., R. Speck, A.H. Göktogan \& S. Sukkarieh 2010. Autonomous airborne wildlife tracking using radio signal strength. In Intelligent Robots and Systems (IROS), 2010 IEEE/RSJ International Conference on (pp. 107-112). IEEE. 
Kuhn, H.W. 1955. The Hungarian Method for the assignment problem. Naval Research Logistics Quarterly, 2: 83-97

Lagerveld, S., B. Jonge Poerink\& H. Verdaat 2014a. Monitoring bat activity in offshore wind farms OWEZ and PAWP in 2013. IMARES Report C165/14.

Lagerveld, S., B.Jonge Poerink, R. Haselager\& H. Verdaat 2014b. Bats in Dutch offshore wind farms in autumn 2012. Lutra 57 (2): 61-69

Lagerveld, S., B. Jonge Poerink \& P. de Vries 2015. Monitoring Bat activity at the Dutch EEZ in 2014. IMARES Report C094/15.

Leopold, M.F., M. Boonman, M.P. Collier, N. Davaasuren, R.C. Fijn, A. Gyimesi, J. de Jong,R.H. Jongbloed, B. Jonge Poerink, J.C. Kleyheeg-Hartman, K.L. Krijgsveld, S. Lagerveld,R. Lensink, M.J.M. Poot, J.T. van der Wal \& M. Scholl 2014. A first approach to deal with cumulative effects on birds and bats of offshore wind farms and other human activities in the Southern North Sea. IMARES Report C166/14.

Munkres, J. 1957. Algorithms for the Assignment and Transportation Problems, Journal of the Society for Industrial and Applied Mathematics, 5(1):32-38

Rerucha S., T. Bartonicka, P. Jedlicka, M. Cížek, O. Hlouša, R Lucan \& I. Horácek 2014. The BAARA (Biologic,al AutomAted RAdiotracking) System: A New Approach in Ecological Field Studies. PLoS ONE 10(2): e0116785. doi:10.1371/journal. pone.0116785

Russel, S. \& P. Norvig 2010. Artificial Intelligence: a Modern Approach (3rd ed.). Pearson Education SER Agreement 2013. http://www.energieakkoordser.nl/doen/engels.aspx [last accessed: December 2017]

Sjöberg, S., T. Alerstam, S. Åkesson, A. Schulz, A. Weidauer, T. Coppack, \& R. Muheim 2015. Weather and fuel reserves determine departure and flight decisions in passerines migrating across the Baltic Sea. Animal Behaviour, 104, 59-68.

Smolinsky, J.A., R. H.Diehl, T.A. Radzio, D.K. Delaney, \& F.R. Moore 2013. Factors influencing the movement biology of migrant songbirds confronted with an ecological barrier. Behavioral Ecology and Sociobiology, 67(12), 2041-2051.

Zhang, Z. 1998. A Flexible New Technique for Camera Calibration. IEEE Transactions on Pattern Analysis and Machine Intelligence, 22(11):1330-1334, 2000. 


\section{Justification}

Report C026/17

Project Number: 43151000.38

The scientific quality of this report has been peer reviewed by a colleague scientist and a member of the Management Team of Wageningen Marine Research

Approved:

Daniel Benden

Researcher

Signature:

Date:

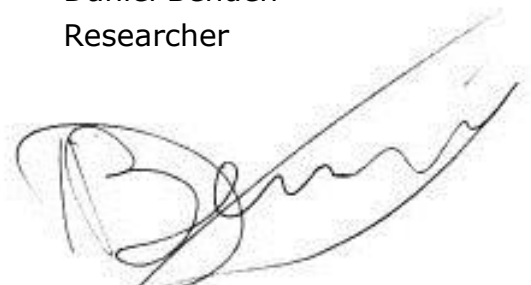

$31,03-2017$

Approved:

Drs. J. Asjes

Member of Management Team

Signature:

Date:

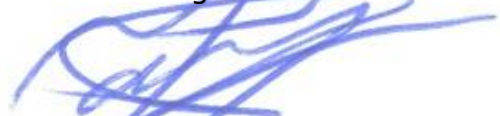

31-03-2017 
Wageningen Marine Research

T +31 (0)317480900

E: marine-research@wur.nl

www.wur.eu/marine-research

Visitors' address

- Ankerpark 271781 AG Den Helder

- Korringaweg 5, 4401 NT Yerseke

- Haringkade 1, 1976 CP IJmuiden
Wageningen Marine Research is the Netherlands research institute established to provide the scientific support that is essential for developing policies and innovation in respect of the marine environment, fishery activities, aquaculture and the maritime sector.

\section{Wageningen University \& Research:}

is specialised in the domain of healthy food and living environment.

\section{The Wageningen Marine Research vision}

'To explore the potential of marine nature to improve the quality of life'

\section{The Wageningen Marine Research mission}

- To conduct research with the aim of acquiring knowledge and offering advice on the sustainable management and use of marine and coastal areas.

- Wageningen Marine Research is an independent, leading scientific research institute

Wageningen Marine Research is part of the international knowledge organisation Wageningen UR (University \& Research centre). Within Wageningen UR, nine specialised research institutes of the Stichting Wageningen Research Foundation have joined forces with Wageningen University to help answer the most important questions in the domain of healthy food and living environment. 